\title{
The gustatory neocortex of the rat
}

\author{
J. JAY BRAUN, PHILLIP S. LASITER, and STEPHEN W. KIEFER \\ Arizona State University, Tempe, Arizona
}

\begin{abstract}
Research findings related to the functional significance of the gustatory neocortical system of the rat are reviewed and interpreted. Studies of gustatory neocortex (GN) involvement in taste-related cognitive processes are emphasized after briefly reviewing GN anatomy and physiology. Evidence is presented supporting the conclusion that the GN contributes relatively little to fundamental taste reactivity, but is deeply involved in cognitive (learning and memorial) taste processes; that is, "reactive salience" to taste stimuli is preserved following GN ablation, while "associative salience" is markedly degraded. Apparent functional similarities between GN and other sensory neocortical areas are emphasized throughout the paper, and a hierarchical view of gustatory system functioning is addressed.
\end{abstract}

Patton began his 1950 review of the chemical senses by pointing out that taste and smell essentially had been neglected relative to the other sensory systems. As a partial explanation for this neglect, he mentioned the technical difficulties in studying the chemical senses, and added that sensory physiologists of the era were perhaps inclined to view taste and smell as "luxury senses, hedonically useful, but biochemically dispensable." Patton went on to identify the studies of Adrian (1942) and Pfaffmann (1941) as signaling a broach of the technical difficulties of studying taste and smell physiology, and Richter's (1942) work on dietary self-selection in rats was noted as having demonstrated a very important role of taste in the bioeconomics of the rat. Modesty may have prevented Patton from adding that his own research on the gustatory system of the monkey was seminal in defining the central neural systems associated with gustatory behavior (e.g., Patton, Ruch, \& Walker, 1944).

During the two decades following Patton's review, work associated largely with Pfaffmann's laboratories (e.g., Pfaffmann, 1959, 1960, 1965, 1970) led to substantial development of a basic understanding

Address reprint requests to J. Jay Braun, Psychology Department, Arizona State University, Tempe, Arizona 85287. Research support was provided by N.I.H. Grants NB06788, NS08658, NS11616, Nutrition Foundation Grant 440 (with W. Kessen and G. Nowlis), and, most recently, by a Dean's Research Award to J.B. (summer 1980), Institutional Biomedical Research Support Grant 935191 to D. Glanzman, and by generous assistance from research funds provided by the Department of Psychology, for which we are most grateful. We deeply appreciate the thoughtful and detailed editorial comments and suggestions offered by Dennis Glanzman, and the patience, skill, and good cheer of Pat Query who typed the manuscript. I (J.B.) should like to express gratitude to my dear friend, Geoffrey Nowlis, whose original ideas contributed to the heuristic framework for much of the research summarized, and the thoughts expressed, in the present paper, and to George Wolf, who first called my attention to the gustatory neocortex of the rat. of sensory encoding in the taste system (see, also, Beidler, 1954, 1962) and of behavioral taste processes (see, also, Rozin \& Kalat, 1971, and Young, 1966). This work led also to important observations concerning the anatomy and physiology of the central gustatory system (see Burton \& Benjamin, 1971), including the delineation of the subject of this review, the gustatory neocortex of the rat, by Benjamin and Pfaffmann (1955).

By 1960, anatomical, electrophysiological, and behavioral evidence had converged to define the focus of the "cortical taste nerve area" of the rat as, approximately, a $1 \times 3 \mathrm{~mm}$ region of cortex bridging the middle cerebral artery adjacent to, but distinctly above, the rhinal sulcus (Benjamin \& Akert, 1959; Benjamin \& Pfaffmann, 1955). In addition, on the basis of relationships established between this area and the medial ventrobasal thalamic nucleus, a classic neuroanatomical criterion of "sensory neocortex" appeared to be fulfilled for the gustatory area (Benjamin \& Akert, 1959; Frommer, 1961). However, confirmation of the rat's gustatory cortical area on the basis of electrophysiological responses to taste stimuli applied to the tongue awaited the works of D. Ganchrow and Erickson (1972) and Yamamoto and Kawamura (1972).

Early behavioral evidence linking GN to gustatory function in the rat used Richter's (1939) two-bottle testing method to evaluate sensitivity to quinine hydrochloride solutions relative to water. Lesions centered on the "taste nerve area" appeared to produce hypogeusia for quinine. However, "islet" preparations, in which all neocortex was ablated, leaving an intact island of GN, did not abnormally influence quinine sensitivity (Benjamin \& Akert, 1959; Benjamin \& Pfaffmann, 1955). Assessments of sensitivity to gustatory cues other than quinine in rats lacking GN were not conducted in the early research, and, with the exception of a brief report in which a taste avoid- 
ance conditioning procedure was employed using electric shock as the aversive stimulus (Benjamin, 1960), likely involvement of the GN in taste learning and memory processes had not been addressed. In fact, prior to about 1970 , there were essentially no systematic studies of the role of forebrain gustatory systems in the cognitive processing (learning and memory) of taste stimuli. In this regard, the spirit of Patton's (1950) observation remained evident: Relative to the wealth of data collected on forebrain involvement in the adaptive processing of visual, auditory, and somatosensory information, there were no similar data concerning cognitive gustatory processes.

Shortly after Patton's (1950) review, flavor aversion learning in rats was discovered (Garcia, Kimmeldorf, \& Koelling, 1955; Richter, 1953; Rzoska, 1953), and a paradigm was elaborated by which animals easily could be trained to avoid specific taste stimuli by pairing a taste solution with an illnessproducing treatment. A virtual explosion of research on taste aversion learning began about 15 years later (see Barker, Best, \& Domjan, 1977; Domjan, 1980), and this undoubtedly contributed to the climate which inspired the initial studies of the role of brain mechanisms in associative taste processes. Probably because of the apparent role played by the limbic system in avoidance behaviors, olfaction, and visceral reactivity (MacLean, 1972; McCleary, 1966; Papez, 1937), the search for brain systems critically involved in taste aversion learning initially focused on this system. These early studies explored the effects of septal lesions (McGowan, Garcia, Ervin, \& Schwartz, 1969), hippocampal lesions (C. R. Miller, Elkins, \& Peacock, 1971), hypothalamic lesions (Gold \& Proulx, 1972; Roth, Schwartz, \& Teitelbaum, 1973), and amygdaloid lesions (Nachman \& Ashe, 1974) on taste aversion learning. Other studies examined the effects of area postrema lesions (Berger, Wise, \& Stein, 1973), electroconvulsive shock (Kral, 1970), and cortical spreading depression (Best \& Zuckerman, 1971). The first study of GN involvement in taste aversion learning appeared also at this time (Braun, Slick, \& Lorden, 1972).

The organizational structure of this review is as follows. It begins with a historical summary of neuroanatomical and neurophysiological investigations regarding gustatory neocortex in the light of the contemporary picture of the central gustatory pathways (see also Pfaffmann, Frank, \& Norgren, 1979). Next, three major categories of research concerning changes in behavioral dispositions toward taste stimuli following GN ablation are individually presented and discussed-taste detection and reflexes, taste learning, and taste memory. A final discussion considers the results of selected studies of other brain mechanisms of taste sensibility as they may relate to gustatory neocortex. Research developments over the past decade are emphasized, and two literatures that have overlapped little in the past, gustatory processes and sensory neocortical function, are addressed.

\section{CENTRAL GUSTATORY PATHWAYS}

Peripheral gustatory fibers of the seventh (facialintermediate), ninth (glossopharyngeal), and tenth (vagus) cranial nerves project directly to the solitary nucleus (SOL). Early studies by Allen (1923), using the Marchi method, suggested this, and subsequent experiments by both Astrom (1953) and Torvik (1956) supported such a conclusion. The course of secondary gustatory fibers, however, remained uncertain for many years, principally because of the difficulty in producing small lesions within this region and/or verifying that experimental lesions involved secondary gustatory neurons within the SOL. Because of these methodological difficulties, the course of secondary gustatory afferents remained open to conjecture. For example, the close association between somatic (i.e., tactile) and gustatory fibers within the lingual nerve (including chorda tympani) suggested to some authors that first-order gustatory afferents reached the trigeminal nucleus as well as the SOL (see, for example, Crosby, Humphrey, \& Lauer, 1962; Ruch, Patton, Woodbury, \& Towe, 1966). With these assumptions, it was easy to assume that secondary gustatory projections either joined with, or were members of, the lemniscal trigeminothalamic pathways, and that gustatory fibers synapsed within the ventrobasal thalamic complex. It was clear to many investigators that gustatory afferents reached VPM thalamus (Patton, 1950), because lesions of either VPM thalamus (Patton et al., 1944) or the dorsal lemniscal tracts (Patton \& Ruch, 1946) produced elevations in quinine detection thresholds (see also Morest, 1967, for a discussion of possible secondary gustatory pathways).

\section{Pontine, Thalamic, and Amygdaloid Projections}

Norgren and Leonard $(1971,1973)$ combined electrophysiological recordings within the SOL and lesiondegeneration analyses to evaluate the course and extent of gustatory projections within the medulla. These experiments demonstrated that fibers of secondary gustatory neurons within SOL synapse within the marginal parabrachial nucleus or "pontine taste area" (PTA). The same series of experiments also demonstrated that fibers of the PTA ascend bilaterally and synapse within the posterior ventromedial nucleus of the thalamus (VPM). These results radically altered contemporary assumptions concerning the trajectory of gustatory afferents within the medulla and midbrain. Because gustatory afferents reached the thalamus via fibers of the reticular formation, and these fibers traversed the central tegmental bundle rather than the me- 
dial lemniscus, it was evident that gustatory afferents were constituents of a reticulothalamic sensory pathway (Norgren \& Pfaffmann, 1975).

Anatomical tracer studies employing tritiated amino acids and/or horseradish peroxidase (HRP) have implicated a much more elaborate network of prosencephalic projections from the SOL than did earlier studies using the Fink and Heimer (1967) method (e.g., Morest, 1967; Norgren \& Leonard, 1971, 1973). Axonal transport studies have shown that the SOL contains somata and/or axons of passage which project to the marginal parabrachial nuclei, central nucleus of the amygdala (CE), the subthalamic nuclei (CN), substantia innominata (SI), anterior hypothalamus (AH), and the bed nucleus of stria terminalis (BST) (Norgren, 1976, 1978; Ricardo \& Koh, 1978). Such findings have served to implicate these projection pathways in gustatory function. However, adequate verification of gustatory responses within these areas has not yet been provided, and anatomical as well as electrophysiological observations suggest that these basal forebrain regions may be preferentially involved in the relay of visceral (gastrointestinal) information rather than of taste information per se (see Norgren, 1968; Ricardo \& Koh, 1978; Voshort \& Van der Kooy, 1981).

Ricardo and Koh (1978) showed that injections of tritiated amino acids into caudal portions of the SOL, which are posterior to gustatory-responsive areas (see Norgren, 1976, 1978), also result in labeling within the CE, SI, BST, and AH. It seems likely, then, that forebrain labeling within these areas following injections within the rostral SOL involves gustatory as well as visceral projections (Norgren, 1978). It is clear, however, based upon electrophysiological observations by many investigators, that gustatory afferents do synapse within the PTA (e.g., Norgren, 1974; Norgren \& Pfaffmann, 1975; Perrotto \& Scott, 1976; Scott \& Perrotto, 1980).

Emmers, Benjamin, and Blomquist (1962) showed that neurons within VPM thalamus can be driven by direct electrical stimulation of the chorda tympani and glossopharyngeal nerves. Neurons located slightly lateral to VPM thalamus are driven only by direct stimulation of the lingual nerve. Such observations indicate that third-order gustatory neurons are located in close proximity to the "somatic facial region" of thalamus. Related experiments in monkey (Blomquist, Benjamin, \& Emmers, 1962) have essentially verified the territories of gustatory and somatic neurons within the ventrobasal complex (see also D. Ganchrow \& Erickson, 1972).

The central nucleus of the amygdala receives direct projections from the PTA as well as the SOL (Voshart \& Van der Kooy, 1981). Neurons associated with amygdaloid projections are located within areas of the PTA which are also occupied by neurons that project fibers to VPM thalamus (see Figures 1 and 3 of Voshart \& Van der Kooy, 1981). Although gustatory responses have not yet been adequately documented within the CE, PTA projections to the CE may provide gustatory input to either the neocortex or the hypothalamus. Injections of tritiated amino acids into the CE result in extensive labeling of the hypothalamus (Krettek \& Price, 1978). Norgren (1970a) has demonstrated that regions of the hypothalamus receive gustatory information. Thus, gustatory information may reach the hypothalamus via projections from the CE. The CE may also convey information to the neocortex, but the data implicating such pathways are unresolved. The studies of Krettek and Price $(1974,1977$ a, 1977b, 1977c, 1978) clearly indicate that the lateral and/or basolateral amygdaloid nuclei project axons to the insular cortex in rat and cat. Lasiter, Glanzman, and Mensah (1982) have confirmed that the gustatory neocortical zone receives projections from the lateral, but not the basolateral, amygdaloid nucleus. Thus, gustatory regions of the neocortex do receive amygdaloid fibers. The studies of Krettek and Price do not, however, demonstrate a projection pathway from the $\mathrm{CE}$ to the lateral nucleus in the rat; the major input to the $C E$ appears to arise from the lateral and basolateral nucleus. It is possible, then, that gustatory afferents reach the neocortex via projections of the amygdaloid complex, but verification of such projection pathways awaits further investigation.

\section{Cortical Projections: Early Research}

While the research of Benjamin and his colleagues (e.g., Benjamin \& Akert, 1959; Benjamin \& Pfaffmann, 1955) presented the strongest case for localizing the cortical taste area within the somatic facial region, these efforts were guided by a substantial number of earlier investigations. Prior to the 1940s there was a tacit assumption that taste information was processed within areas of the parahippocampus and allocortex. Early observations by Ferrier (1886) had implicated the subiculum in taste-guided behavior. Other authors (e.g., Ladd, 1887) agreed that the temporal gyrus was largely related to feeding behaviors. This notion persisted for some time, irrespective of experimental data. Thus, a long-standing notion prevailed which suggested that gustatory and olfactory information was integrated within areas of the rhinencephalon. This assumption is evidenced in classic neuroanatomical textbooks (e.g., Crosby et al., 1962) by the conclusion that "olfactogustatory" areas existed within the temporal allocortex.

In the early 1940s, Börnstein (1940a, 1940b, 1940c) challenged the assumptions that gustatory information was received and integrated within the temporal allocortex. In a consideration of both clinical and experimental data, it appeared to Börnstein that a gustatory region was located within the ventral postcentral operculum or parainsular cortex, rather than 
within the temporal allocortex. This early rejection of classic neuroanatomical doctrine was so controversial at the time that later authors (e.g., Bagshaw \& Pribram, 1953; Patton, 1950), in reviewing the empirical data, "vindicated" Börnstein's abrogations. Historically, then, it was the rejection of classic assumptions concerning the rhinencephalic representation of taste that initiated empirical efforts toward defining the cortical taste area more explicitly.

Shortly following Börnstein's analysis, Patton and colleagues began systematic studies of the gustatory cortical region in both simian and feline species (Patton, 1950, 1955; Patton \& Amassian, 1952; Patton, Ruch, \& Fulton, 1946). These experiments employed ablation techniques or electrophysiological methods to localize the cortical taste area. In behavioral analyses, it was generally found that pathological insult to the insula, or to the parainsular cortices, produced either transient or permanent increases in quinine rejection thresholds. The most critical cortical issue appeared to lie in close proximity to the claustrum, either deep within the insula or at the margin of the ventral postcentral operculum. Injury to the superior or paratemporal operculum did not induce similar effects. Electrophysiological experiments in the cat also implicated portions of this region. Direct electrical stimulation of the chorda tympani elicited evoked potentials slightly anterior to the ventral paracentral cortical area. The discrepancy in results between behavioral and electrophysiological experiments was reconciled by the observation that the chorda tympani contained both tactile and gustatory fibers, and recruitment of the tactile fibers was thought to produce a more anterior cortical focus (Patton \& Amassian, 1952; see also Ruderman, Morrison, \& Hand, 1972). Thus, within a period of 10 years, the gustatory cortical area had been relocated from the temporal allocortex to regions in or near the somatic facial region (Patton \& Ruch, 1946) in infrahuman species.

A substantial proportion of anatomical and electrophysiological data indirectly implicated the ventral paracentral cortical area in gustation, based upon established topographical territories of thalamic (i.e., VPM) projections. The studies of Walker (1934, 1938), using the Marchi method, established that the ventrobasal complex contained cells which project axons to the ventral paracentral operculum. Blum, Ruch, and Walker (1943) subsequently provided experimental evidence which implicated the ventrobasal complex of monkey in taste sensibility. Because thalamocortical projections were known to exist between the medial ventrobasal complex and the paracentral operculum, and pathological insult to this thalamic region produced hypogeusia, it was accepted prima facie by many investigators that gustatory information did reach the somatic facial areas (Patton, Ruch, \& Walker, 1944).

Prior to 1955 , no studies of the gustatory cortical region had been conducted on the rat. Selection of the monkey as the preferred subject for behavioral ablation experiments primarily reflected contemporary research tactics, but the use of primates with well-developed cortical convolutions presented a number of methodological problems. For example, it was recognized by Bagshaw and Pribram (1953) that projections from thalamus to insula could be damaged via aspiration of deep cortical tissue of the superior temporal gyrus, and this factor could possibly complicate the localization of cortical gustatory function. As suggested by Benjamin and Akert (1959), the lissencephalic brain of the rat offered obvious advantages in terms of producing precise cortical lesions, or conducting surface cortical electrophysiology. The use of this species did, however, prevent detailed comparative analyses, since the insular cortical areas are not topically defined.

\section{The Gustatory Neocortex}

The studies of Benjamin and colleagues (1955, 1959) represented a major synthesis of anatomical, electrophysiological, and behavioral data which localized more fully the gustatory cortex within the somatic facial field and/or insula in rat. Initial experiments by Benjamin and Pfaffmann (1955) employed direct electrical stimulation of both the chorda tympani and glossopharyngeal nerves to define the boundaries of the cortical taste nerve area. Stimulation of these nerves produced a cortical focus within adjacent, but overlapping, regions of the somatic facial region that had been previously described by Woolsey and LeMessurier (1948). Ablation of the ventral portion of this composite region produced elevations in the rejection threshold to quinine drinking solutions. Finally, subsequent experiments (Benjamin \& Akert, 1959) evaluated retrograde cellular degeneration within the diencephalon which was associated with quinine detection deficits. Although the conclusions afforded by degeneration analyses using the Nissl method were tentative at the time (Benjamin \& Akert, 1959), these authors concluded that degeneration of a limited population of neurons within posterior ventromedial thalamus were best correlated with quinine detection deficits. Thus, the results obtained by Benjamin and his associates suggested that the gustatory cortical region in rat was located in or near regions previously implicated in monkey and cat.

At least three major categories of neuroanatomical, behavioral, and electrophysiological studies followed as a result of the studies of Benjamin and his colleagues. First, gustatory thalamocortical projections from VPM thalamus to somatic facial areas were functionally defined. Wolf (1968) employed electrophysiological recordings within the VPM thalamus to localize populations of gustatory neurons. Following these procedures, small electrolytic lesions were produced within VPM and tissue was subsequently ana- 
lyzed with the silver-degeneration method of Nauta (1957). These results essentially corroborated the findings of Benjamin and Akert (1959), in that fiber degeneration was traced to the facial somatic region. In later experiments, Norgren and Wolf (1975) employed similar techniques, but included sapid stimulation of the tongue and the more sensitive argyrophilic reaction of Fink and Heimer (1967). The results of this study also indicated that gustatoryresponsive neurons within the VPM thalamus project fibers to analogous regions of the cortex, as defined by Benjamin and his colleagues.

Second, restricted lesions of the VPM thalamus were shown to elevate quinine detection thresholds (Ables \& Benjamin, 1960) in the rat. These data suggested that, in the rat and monkey, the VPM thalamus is essential for the perception and/or appreciation of gustatory stimuli.

Finally, electrophysiological recordings of both single and multiple cortical units within the gustatory area have been conducted (e.g., D. Ganchrow \& Erickson, 1972; Norgren \& Wolf, 1975; Yamamoto \& Kawamura, 1972; Yamamoto, Matsou, \& Kawamura, 1980; Yamamoto, Yuyama, \& Kawamura, 1981). These data indicate that lingual information reaches the somatic facial region, but that somatic as well as gustatory neurons are represented within the same cortical area. Cortical neurons within the "chorda tympani area" respond to taste, touch, temperature, and/or combinations of these stimuli, but neurons responding specifically to the taste component appear to be located at the more ventral and posterior portion of the composite taste area defined by Benjamin and Pfaffmann (1955). Figure 1 summarizes the afferent gustatory pathways. Figure 2 depicts the composite gustatory cortical area in rat.

\section{An Insular Gustatory Area?}

The comment by Zotterman (1970) that "it is still not certain where taste projects to the cortex" remains at least partially justified, even though the neocortex of the rat has been subjected to considerable insult since that time. Although many investigators have suggested that the somatic facial region (SS I) contains the gustatory cortex (e.g., Emmers, 1966; Norgren \& Wolf, 1975), particular data also implicates the insular cortex as an additional gustatory cortical region in the rat.

Benjamin and Akert (1959) recognized that the most crucial cortical area for taste sensibility appeared to be that of the insular cortex. This conclusion was based upon the observation that cortical aspirations that encroached upon cortical tissue near the claustum produced the most severe quinine hypogeusia. Such observations by Benjamin and Akert (1959) had important comparative implications at the time, in that there was at least some indication that

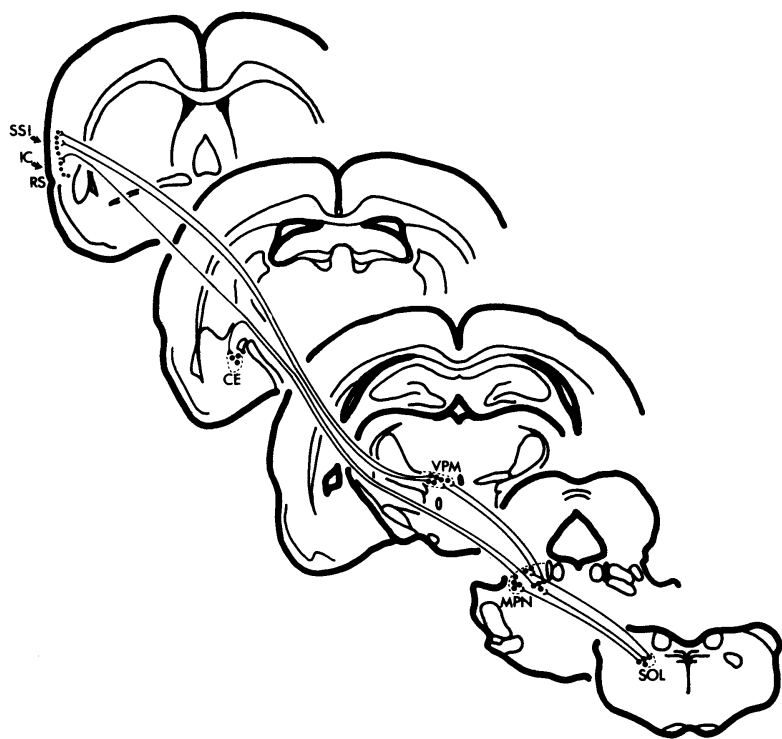

Figure 1. Summary of afferent gustatory pathways. Note that only unilateral projections are depicted for ease of visualization. Projection pathways to the central nucleus of amygdala have also been included in this diagram, but it should be emphasized that gustatory-responsive neurons within amygdaloid regions have not been verified. Abbreviations are: $\mathbf{C E}$, central nucleus of amygdala; IC, insular cortex; MPN, medial parabrachial nucleus; RS, rhinal sulcus; SOL, solitary nucleus; SSI, primary somatosensory neocortex; VPM, posterior ventromedial nucleus of thalamus.

the cortical taste region in monkey and rat was located in homologous cortical areas.

In a recent anatomical, electrophysiological, and behavioral study, Yamamoto et al. (1980) described at least three distinct cortical areas which receive gustatory information. Electrical and/or chemical stimulation of the tongue produced evoked potentials within an anterior chorda tympani and lingual nerve area (CT-LN), a dorsal glossopharyngeal nerve area, and a ventral glossopharyngeal nerve area (see Figure 1 and Yamamoto et al., 1980, for the exact locations of these areas). In the same study, lesions of the dorsal glossopharyngeal area did not produce deficits in the retention of a preoperatively instated conditioned taste aversion (CTA) (see subsequent portions of this paper for a further discussion of these behavioral effects), whereas lesions of the rhinal bank produced CTA retention deficits. Thus, lesions within the rhinal bank were sufficient to disrupt the retention of CTA. Because the lesions in this study were produced by aspiration, it is very likely that neuronal pathology occurred to the insular cortices as well as ventral SS I (see Figure 8 of Yamamoto et al., 1980, and Figure 5 of Krettek \& Price, 1977a). Although these authors previously had recognized that this area could be defined as the insula in rabbit (Yamamoto \& Kawamura, 1975), they did not reemphasize the role of the insular cortex in CTA retention in their later study (Yamamoto et al., 1980, see p. 450). 
Posteroventral gustatory areas that correspond to the "glossopharyngeal area" of the Yamamoto et al. (1980) study receive direct projections from the pontine taste area (Lasiter, Glanzman, \& Mensah, 1982). In our initial anatomical report, applications of HRP to the somatic gustatory region produced retrograde labeling of PTA neurons only if gustatory cortical areas posterior to the MCA were invaded. Subsequent anatomical experiments (Lasiter \& Glanzman, Note 1) have shown that the insular cortex surrounding the middle cerebral artery in the rat receives a significant number of monosynaptic projections from the PTA, and collateral axons of pontocortical projections also reach VPM thalamus. Combined anatomical and behavioral experiments have also shown that the somatic gustatory region does not obviously contribute to conditioned taste aversion acquisition (Lasiter \& Glanzman, 1982), whereas lesions involving the insular cortices do consistently produce conditioned taste aversion acquisition deficits.

As suggested by Yamamoto et al. (1980) and by Burton and Benjamin (1971), at least two distinct cortical gustatory areas may exist, and these cortical areas may be located within both the ventral somatosensory field and the insula. On the other hand, the results of Ruderman et al. (1972) may predict the problems which may be encountered when attempting to localize the gustatory cortical area via stimulation of either the chorda tympani or glossopharyn-

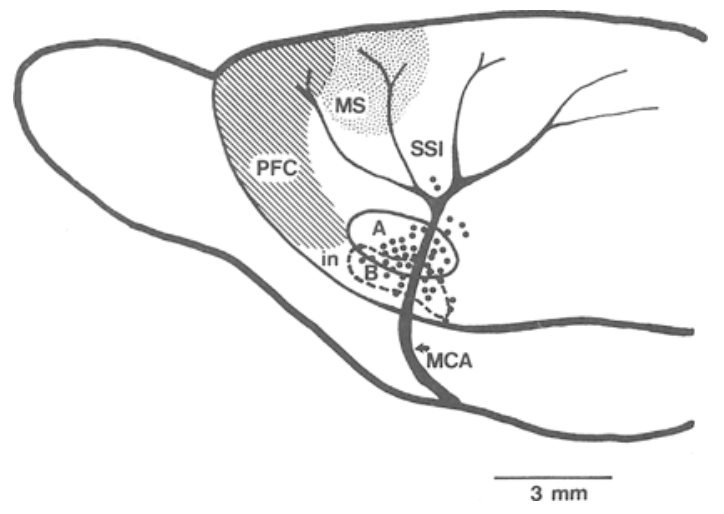

Figure 2. Composite gustatory cortical region as delimited by several previous studies. Circumscribed regions in A represent the somatic gustatory cortical area defined by Benjamin and Pfaffmann (1955). Region B approximates the location of anterograde degeneration following restricted lesions of gustatoryresponsive regions of the posterior ventromedial nucleus of thalamus (Norgren \& Wolf, 1975). Filled circles are the combined electrophysiological results of Yamamoto and Kawamura (1972) and Yamamoto, Yayama, and Kawamura (1981). Note that the results of Yamamoto and associates demonstrate that gustatoryresponsive neurons are located within both the somatic and insular cortices. Abbreviations are: in, insular cortex (areas 13 and 14); MCA, middle cerebral artery; MS, motor cortex; PFC, prefrontal cortex; SSI, primary somatosensory neocortex. geal nerves. Concerning the localization of the cortical gustatory area in cat, Ruderman et al. (1972) concluded that: "In view of the present work, the most reasonable explanation for the past difficulties in evoking cortical responses by natural (sapid) stimulation in the cat is that the region explored by earlier workers was not the appropriate one" (p. 533). It should be emphasized that the anterior somatic gustatory area (e.g., Benjamin \& Akert, 1959; Yamamoto et al., 1980) may be less involved in taste-guided behaviors than the insular cortex posterior to the MCA (see also D. Ganchrow \& Erickson, 1972). This possibility is supported by the locations of cortical neurons responding to tactile, thermal, and taste stimuli reported by Yamamoto et al. (1981): Units located within the insula, posterior to the MCA, appear to respond almost exclusively to taste stimuli.

\section{TASTE DETECTION AND CONCENTRATION RESPONSE FUNCTIONS}

In 1975, we briefly reported the results of taste sensitivity tests for rats lacking gustatory neocortex (Braun \& Kiefer, 1975). These studies were designed to determine whether a case could be made for taste reactivity differences between normal and GNablated rats for any of the four basic taste qualities (see Bartoshuk, 1971; McBurney, 1974). Because of the increasing importance of this work as a foundation for subsequent functional analyses of $\mathrm{GN}$, we present a summary of the data and our procedures, below.

\section{Method}

Eighty-five male Long-Evans hooded rats were reared in individual cages from weaning (30 days of age) with ad-lib food and distilled water. At approximately 80 days of age, the rats were matched by weight and randomly assigned to one of four groups. An unoperated-control group was anesthetized but not surgically treated. A lesion-control group was subjected to bilateral ablation of approximately $25 \%$ (surface area) of neocortex dorsal to the gustatory areas, involving, to some degree, both somatosensory and visual neocortex but completely sparing the GN. The remaining two groups were subjected to bilateral ablations of anterolateral neocortex centered on the $\mathrm{GN}$, as classically defined by Benjamin and Pfaffmann (1955). One group received ablations defined as "small" (involving up to $15 \%$ of the surface of the neocortex), and the other received "large" ablations (up to 25\%) which were intended to extend well beyond the gustatory area in dorsal, anterior, and posterior planes (see Figure 3). Benjamin and Akert (1959) had mentioned that while removal of almost all neocortex except GN did not affect quinine sensitivity, complete neocortical ablations that included GN caused elevated quinine thresholds beyond those seen for rats with GN ablations only. We thought that the "large" lesions might reveal such an amplified effect in our tests. In both sets of gustatory lesions, we attempted to avoid extensive invasion of the lateral frontal area because of the feeding and drinking deficiencies produced by ablation of this area (Braun, 1975; Kolb \& Nonneman, 1975).

After 30 days of postoperative recovery, with ad-lib food and distilled water, the rats were placed on a restricted drinking schedule. The schedule involved presenting one bottle of distilled water for 

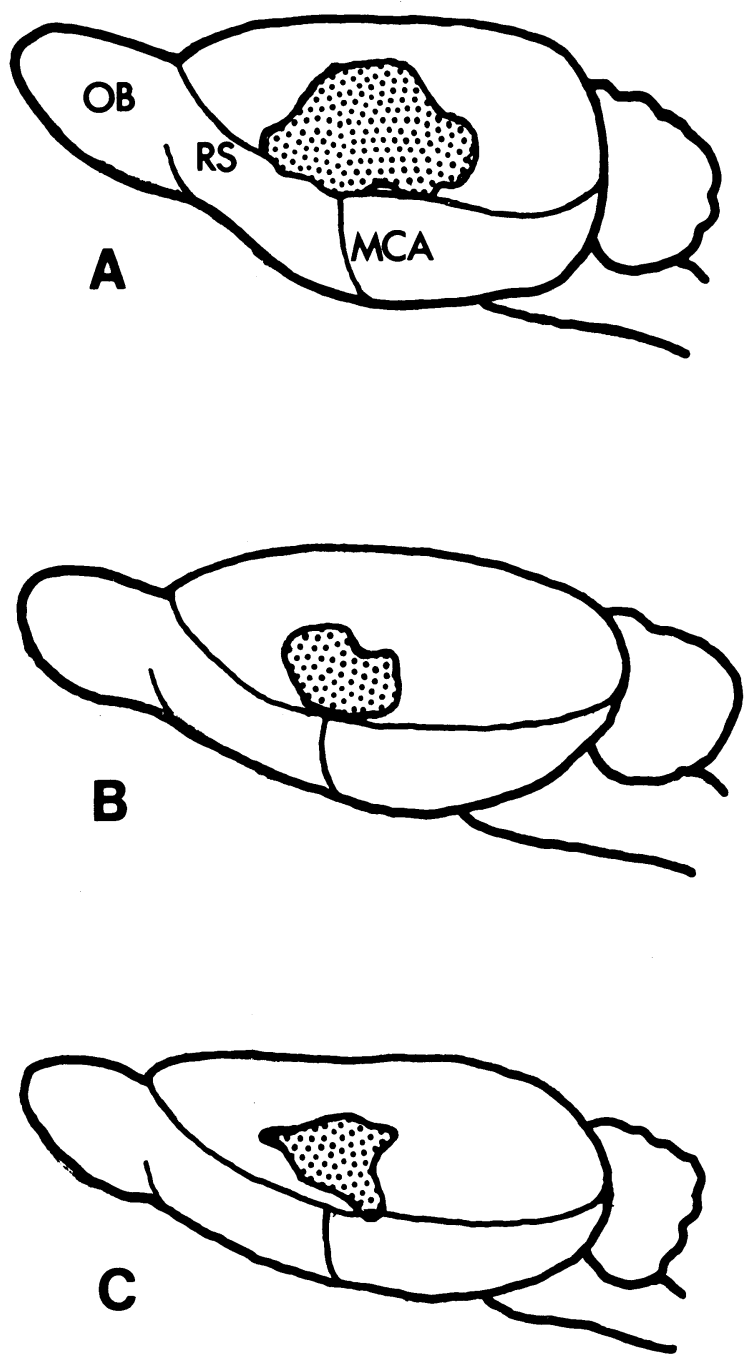

Figure 3. Camera drawings of the surface extent of representative "large" (A) and "small" GN lesions (B and C). The lesion depicted in $\mathrm{C}$ provides an example of spared cortical tissue along the suprarhinal bank adjacent to the $G N$. $O B=$ olfactory bulb; RS = rhinal sulcus; $M C A=$ middle cerebral artery .

$15 \mathrm{~min}$ at 8 a.m. and again for $30 \mathrm{~min}$ at 2 p.m. during adaptation to the schedule (Days 1-7). This deprivation schedule was mild, having little noticeable effect on weight regulation after the first week of adjustment, but insured that the rats would drink without hesitation in the morning. Throughout 122 days of experiments using one-bottle tests, the morning period was used as the "taste test session," whereas only distilled water was presented during the afternoon period. The duration of the morning session represented a compromise between the objective of having a long enough drinking period to optimize measurement of differences in consumption of various taste stimuli and the objective of having it short enough to minimize contributions of postingestional factors (e.g., McCleary, 1953; Mook, 1963) to the amount consumed during taste test sessions. The afternoon session allowed the rats to compensate for excessive rejection or acceptance of taste solutions during the morning test session; this helped minimize confounding the results of the taste tests with varying levels of thirst.

Measurements were taken for 6 months according to the sched-

ule outlined in Table 1. Aware of concerns regarding the sensitivity of taste preference and threshold measures to the methods employed (Stellar \& McCleary, 1952; Young, 1966), we chose to analyze concentration response functions over a wide range of concentrations of stimuli from each of the basic taste categories rather than use discrete definitions of threshold as had been done in the original studies (e.g., Benjamin \& Pfaffmann, 1955). In addition, we used one-bottle tests because of their simplicity relative to two-bottle tests. This reduces the potential intrusion of learning factors-such as memory for position of a preferred bottle and learning to dilute relatively unpalatable taste solutions by alternate sampling of two bottles, one containing water-which could affect the measurements. In addition, it is possible that a "water taste" (Bartoshuk, 1968; Zotterman, 1956) could develop during a test session after a number of licks of a taste bottle and an immediate shift to the water bottle.

Four-taste tests. Because taste response tendencies might change with age and experience over the 6-month testing period, we sampled the rats' responses to a moderately high intensity of each taste quality several times throughout the testing period. This allowed the detection of possible differences between groups in taste reactivity over time. These assessments were called "fourtaste tests" and consisted of periodically presenting, according to a balanced Latin square design, distilled water, sucrose (125 mM), quinine hydrochloride $(.1 \mathrm{mM}), \mathrm{NaCl}(205.2 \mathrm{mM})$, and $\mathrm{HCl}$ $(20 \mathrm{mM})$, one fluid per test session, for five test sessions. The first test series was a four-taste test (Days 8-12) which served to familiarize the rats with the taste qualities and provided preliminary measures of taste reactivity when the rats were relatively naive. To assess changes over time, additional four-taste tests were conducted, as shown in Table 1.

Concentration response functions. Interspersed between the four-taste tests were measures of concentration response functions for sucrose, quinine hydrochloride $(\mathrm{QHCl}), \mathrm{NaCl}$, and $\mathrm{HCl}$ solutions. Nine concentrations of each taste category were selected to

Table 1

Testing Sequence for Taste Reactivity Tests

\begin{tabular}{ll}
\hline Days $\quad$ Measure \\
\hline
\end{tabular}

$1-7$

8-12

14-23

25-34

\section{$36-40$}

$42-51$

$53-62$

64-68

70-79

$81-90$

92-101

103-112

114-118

$120-129$

$131-138$

139-158

161-180
Adaptation to drinking schedule. Distilled water only.

Four-taste Test 1.

Sucrose concentration response functions.

Quinine hydrochloride concentration response functions.

Four-taste Test 2.

$\mathrm{NaCl}$ concentration response functions.

$\mathrm{Hcl}$ concentration response functions.

Four-taste Test 3.

Sucrose threshold test.

Quinine hydrochloride threshold test.

$\mathrm{NaCl}$ threshold test.

Hcl threshold test.

Four-taste Test 4.

Replication of original sucrose concentration response function (Latin square).

Note-See text for explanation of the various tests employed in these experiments. 
represent a broad range of responses in normal rats (Pfaffmann, 1960) from near threshold to clear rejections for each taste (see Table 2). ${ }^{1}$ The presentation of each set of concentrations for a particular taste was such that all concentrations were presented to each group of rats on any one day, two rats per concentration per group. From the first to the last day of testing, the concentrations were presented in an ascending order for each rat until the highest concentration was reached. On the next day, distilled water was presented, and the taste concentrations were again increased over days up to the concentration used prior to the one with which the individual rat had begun the series. The mean of three presentations of distilled water, one on the day before beginning a concentration series for a taste quality, one during the series, and one at the end of the series, constituted the "baseline" of water drinking for each rat.

A replication. Near the end of the study (Days 120-129), we replicated the original sucrose concentration response tests, using a balanced Latin square presentation $(10 \times 10)$ of the nine sucrose concentrations and distilled water. This was done to test the possibility that the ascending series of concentration presentations in the original test may have been responsible for differences that we had observed between normal and $\mathrm{GN}$-ablated rats.

One-bottle threshold tests. After assessing the initial concentration response functions, each taste category was reassessed by selecting a series of concentrations that represented the weaker concentration range of each taste quality. These concentrations are identified in Table 2. These tests were an attempt to find a concentration point for any or all tastes at which rats lacking GN would clearly drop to baseline, while the control groups would continue to show clear discrimination from water at that concentration point. The tests were conducted as before, using the new set of nine concentrations of each taste. In these tests, the lowest concentrations were substantially lower than in the previous concentration response series. In addition, as can be seen in Table 2, new concentrations intermediate between those at the low end of the previous concentration series were used to provide a more fine-grained assessment of the rats' responses to low concentrations.

Two-bottle tests. Finally, we conducted a series of two-bottle preference tests using sucrose and quinine taste stimuli and assessing

Table 2

Taste Concentrations (in Millimoles) Used in Taste Reactivity Tests

\begin{tabular}{cccc}
\hline Sucrose & QHCl & $\mathrm{NaCl}$ & $\mathrm{HCl}$ \\
\hline $1.2 \ddagger$ & $.002 \ddagger$ & $4.9 \dagger$ & $.8 \dagger$ \\
$2.5 \ddagger$ & $.003 \dagger$ & $9.9 \dagger$ & $1.6 \dagger$ \\
$2.6 \dagger$ & $.004 \ddagger$ & $14.9 \dagger$ & $2.5^{*} \dagger$ \\
$5.0 \ddagger$ & $.006 \ddagger$ & $19.9 \dagger$ & $3.3 \dagger$ \\
$5.2 \dagger$ & $.007 \dagger$ & $24.9 \dagger$ & $4.1 \dagger$ \\
$7.7 * \dagger$ & $.008 \ddagger$ & $25.6^{*}$ & $5.0^{*} \dagger$ \\
$10.3 \dagger \ddagger$ & $.010^{*} \dagger \ddagger$ & $29.9 \dagger$ & $5.8 \dagger$ \\
$12.9 \dagger$ & $.013 \dagger$ & $39.9^{*} \dagger$ & $6.6 \dagger$ \\
$15.5^{*} \dagger$ & $.017 \dagger$ & $49.9 \dagger$ & $7.5^{*} \dagger$ \\
$20.0 \ddagger$ & $.020^{*} \dagger \ddagger$ & $51.3^{*}$ & $10.0^{*}$ \\
$20.7 \dagger$ & $.026 \dagger$ & $59.9 \dagger$ & $20.0^{*}$ \\
$25.9 \dagger$ & $.034 \dagger$ & $102.6^{*}$ & $30.0^{*}$ \\
$30.0 \ddagger$ & $.040^{*} \dagger \ddagger$ & $153.8^{*}$ & $40.0^{*}$ \\
$31.0^{*} \dagger$ & $.060 \ddagger$ & $205.2^{*}$ & $50.0^{*}$ \\
$60.0 \ddagger$ & $.070^{*}$ & $359.0^{*}$ & $60.0^{*}$ \\
$62.5^{*}$ & $.080 \ddagger$ & $461.6^{*}$ & \\
$125.0^{*} \ddagger$ & $.100^{*} \ddagger$ & $564.2^{*}$ & \\
$250.0^{*}$ & $.200^{*}$ & & \\
$500.0^{*} \ddagger$ & $.400^{*}$ & & \\
$750.0^{*}$ & $.700^{*}$ & & \\
$1000.0^{*} \ddagger$ & $1.000^{*}$ & & \\
\hline
\end{tabular}

*Concentrations used in initial one-bottle tests. TThreshold one-bottle tests. $\quad \ddagger$ Two-bottle tests. each against distilled water. For these tests, the rats were adapted for 1 week to a new schedule of fluid access consisting of one 30-min period per day and using two bottles of distilled water. Then, after adaptation, they were presented with a series of twobottle tests, with one bottle containing a sucrose solution and the other, distilled water. On each day, half of the rats received the sucrose on the left, and the other half, on the right. The various concentrations of sucrose were presented in a descending order over 20 days. Each concentration was presented twice to each rat: once on the left and once on the right, on consecutive days. The two-bottle sucrose tests were followed by 2 days of distilled water only. Then two-bottle tests of quinine were conducted, using the same format as that used with sucrose. This procedure was somewhat similar to the two-bottle technique used by Benjamin and Pfaffmann (1955) in their assessments of GN function, except that our rats were tested under deprivation, over short drinking periods, and we sampled an entire range of concentrations rather than stopping when a criterion "threshold" measure had been reached.

\section{Results and Discussion}

The results summarized in Figures 4 through 7 do not support a case for taste detection changes associated with GN ablation. However, although rats lacking GN appeared normal in taste reactivity to low concentrations, they tended to be hyperresponsive to moderate and high concentrations of both $\mathrm{NaCl}$ and sucrose. The hyperresponsiveness increased up to a peak at which rejection processes appeared to become dominant (Pfaffmann, 1969); the GN-lesion functions then tended to converge with normal functions. There were no intimations of such changes in rats with control lesions, and "large" vs. "small" GN ablations could not be differentiated by these behavioral measures. For these reasons, the two control groups were collapsed for presentation here, as were the two GN-ablated groups. In addition, there were no major differences in baseline water consumption between control (e.g., Day 7, mean $\mathrm{ml}=13.4 \pm .4$ SEM) and $\mathrm{GN}$-ablated (12.5 \pm .6$)$ groups.

The "peak" concentration responses to $\mathrm{NaCl}$ and sucrose were calculated for each rat. These were arbitrarily defined as the concentration for which consumption was greatest (taking the mean concentration in cases of ties). A significant mean $\mathrm{mM}( \pm$ SEM) difference in peak concentrations was found between control (salt, 163.8 \pm 14.1 ; sucrose, 207.1 \pm 3.1 ) and GN-ablated (salt, $240 \pm 14.1$; sucrose, $323.2 \pm 8.5$ ) groups for both salt and sucrose. An upward shift in the rejection threshold for $\mathrm{NaCl}$ stimuli had been noted earlier in rats with GN lesions (Kawamura, Kasahara, \& Funakoshi, 1970), indicating that the effect is reliable across experiments using different taste assessment procedures. Thus, the only clear case for a "threshold" difference that can be made on the basis of these data is for rejection thresholds of sucrose and $\mathrm{NaCl}$. But the data do not suggest changes in detection thresholds for any of the taste stimuli. In fact, from the responses to low concentrations of $\mathrm{NaCl}$ summarized in Figure 4, it can be seen that a definition of threshold could be arbitrarily selected to support the unreasonable conclusion that 


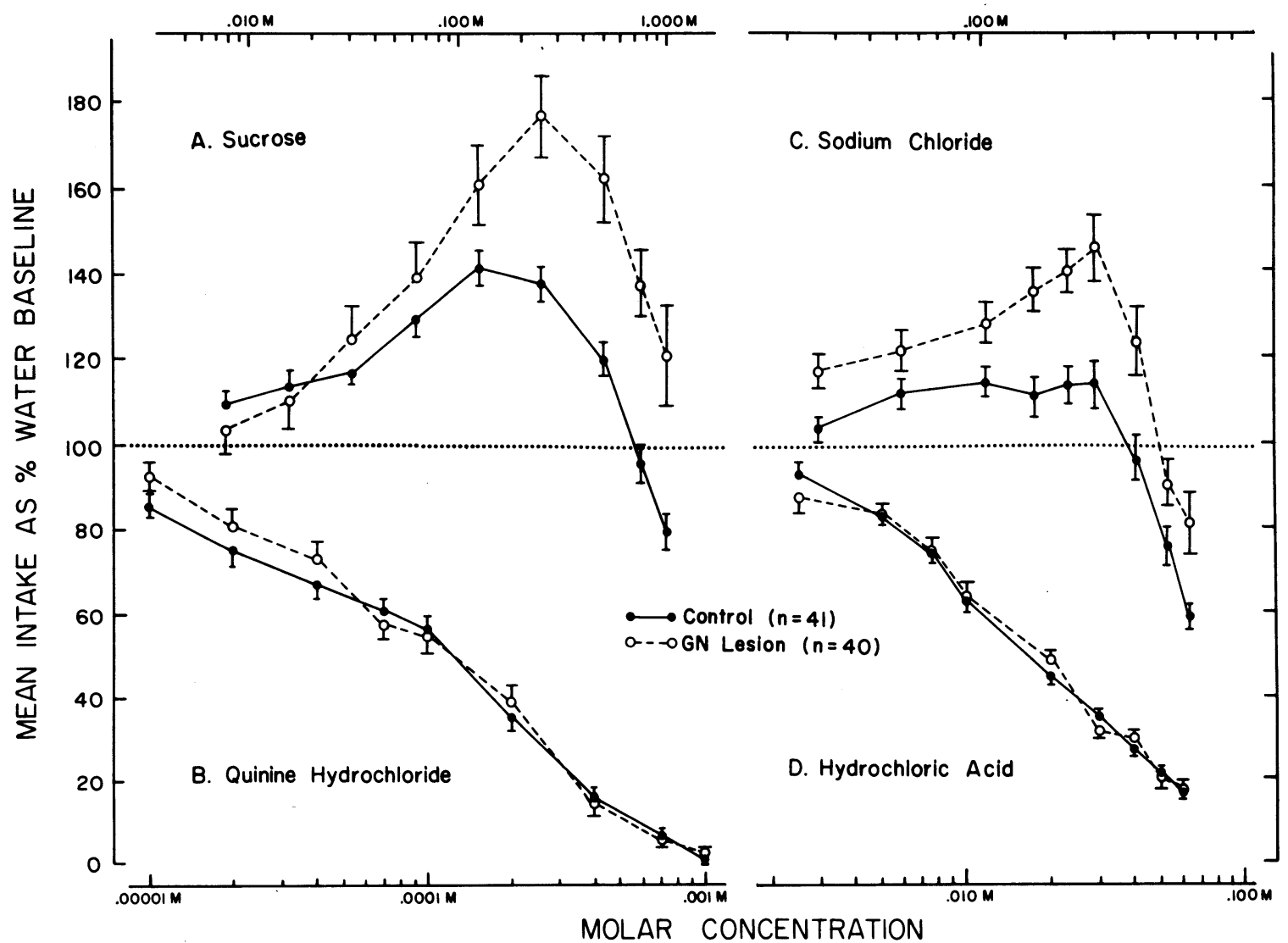

Figure 4. Mean \pm SEM concentration response functions for rats lacking GN and for control groups (one-bottle tests). The dotted line at $100 \%$ on the ordinate represents the point at which the consumption of a taste solution would be equivalent to mean water consumption. The two control groups were combined, as were the two GN-ablated groups, for this presentation.

there was a decrease in the detection threshold following GN ablations.

Figure 5 presents the results of the Latin square replication of the sucrose functions and shows that the relative responsiveness of the two groups to sucrose is essentially the same, but with somewhat less vigorous responses to moderate concentrations and lower rejection thresholds than in the original series of tests. Thus, the differences between groups were not a product of peculiarities of the original design used for assessing the responses to sucrose.

In view of the possibility, however, that we had not captured the relevant concentration range for which indications of detection differences might become apparent, we repeated the study, as described, using a larger number of low concentrations for each of the four taste stimuli (see concentrations marked " $\dagger$ " in Table 2), with the results portrayed in Figure 6. For both sucrose and $\mathrm{NaCl}$, mean consumption by the control group became indiscriminable from baseline at higher concentrations than did the mean consumption by the $\mathrm{GN}$-ablated group. In addition, no taste reactivity differences were evident in the comparisons of the control and $\mathrm{GN}$-ablated groups for quinine and acid stimuli. It remains to be determined whether this conclusion generalizes to the results of other simple methods of testing reactive taste responses, methods with a low likelihood of confounding associative factors with basic preference and aversion responses.

The results of the two-bottle tests (see Figure 7), which were conducted after the rats were highly experienced with the taste stimuli, generally supported the conclusions obtained with one-bottle tests. Rats lacking GN were hyperresponsive to higher concentrations of sucrose while being essentially no different from control rats when tested at low concentrations. And while there is a slight, but consistent, tendency for rats lacking GN to show less avoidance of quinine than control rats, in the direction that would be expected from the original results with quinine (Benjamin \& Pfaffmann, 1955), the difference is not compelling. Perhaps, however, a greater difference would have been observed if the rats had been naive and/or undeprived (Benjamin, 1955b, 1959).

The "four-taste tests" were conducted to monitor changes in responsiveness to suprathreshold sample 


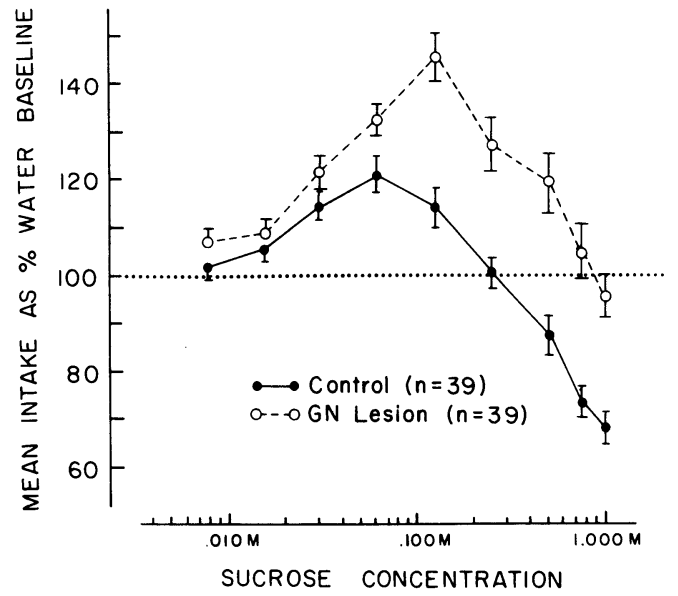

Figure 5. Replication of the one-bottle concentration response functions for sucrose using a balanced Latin-square design. This experiment was conducted 3 months following the sucrose experiment portrayed in Figure 4, using the same groups of rats (see Table 1).

concentrations of each taste quality throughout the testing period. The results (Figure 8) revealed interesting similarities between the two groups of rats. Initial preferences for the sucrose and the salt stimulus in both groups diminished substantially on subsequent tests. These changes may have been due to learned adjustments of intake on the basis of experience with osmotic or metabolic postingestional stress following excessive drinking of sucrose and salt solutions (Jacobs, 1961; McCleary, 1953). For example, excessive drinking of the initially highly palatable, hypertonic $\mathrm{NaCl}$ and sucrose solutions is likely to produce excessive thirst which would probably develop after the 15-min test session and would not be resolved until $6 \mathrm{~h}$ later during the afternoon watering session. Rats lacking GN, having a higher initial responsiveness to the salt solution, have also a greater adjustment to learn in this experimental situation and, presumably, greater postingestional distress: thus, the initial convergent tendency of the curves. This interpretation therefore suggests that the similarity of the two functions for sucrose and $\mathrm{NaCl}$ indicates that normal and $\mathrm{GN}$-ablated rats respond similarly to previous experience with taste stimuli. However, the slight rise in the functions between the third and fourth presentations is difficult to interpret except to note that a greater period of time intervened between these trials than between any other two successive presentations. Perhaps this change with experience represents what could be called a "learned taste equilibrium": an adjustment of intake against hedonic tendencies and thirst factors on the basis of negative motivational consequences associated with prior osmotic stress.

The change in responsiveness to quinine exhibited by control, but not GN-ablated, groups (Figure 8 ) was observed previously over a 4-day period of consecutive familiarization presentations of $.1 \mathrm{mM}$ quinine (Kiefer \& Braun, 1977). Therefore, normal rats display "neophobia" (Barnett, 1958; see, also, Corey, 1978) for initial presentations of quinine, which habituates with experience, and rats lacking GN do not display neophobia to this concentration of quinine. We considered the possibility that the initial reactivity differences between normal and $\mathrm{GN}$-ablated rats to quinine was a factor in the apparent threshold differences for quinine originally reported by Benjamin and his colleagues. However, the data presented by Benjamin and Pfaffmann (1955, Tables 1 and 2) over a 4-month period of testing does not support this suggestion because hypogeusia persisted with little obvious decline. Apparently, however, the quinine reac-

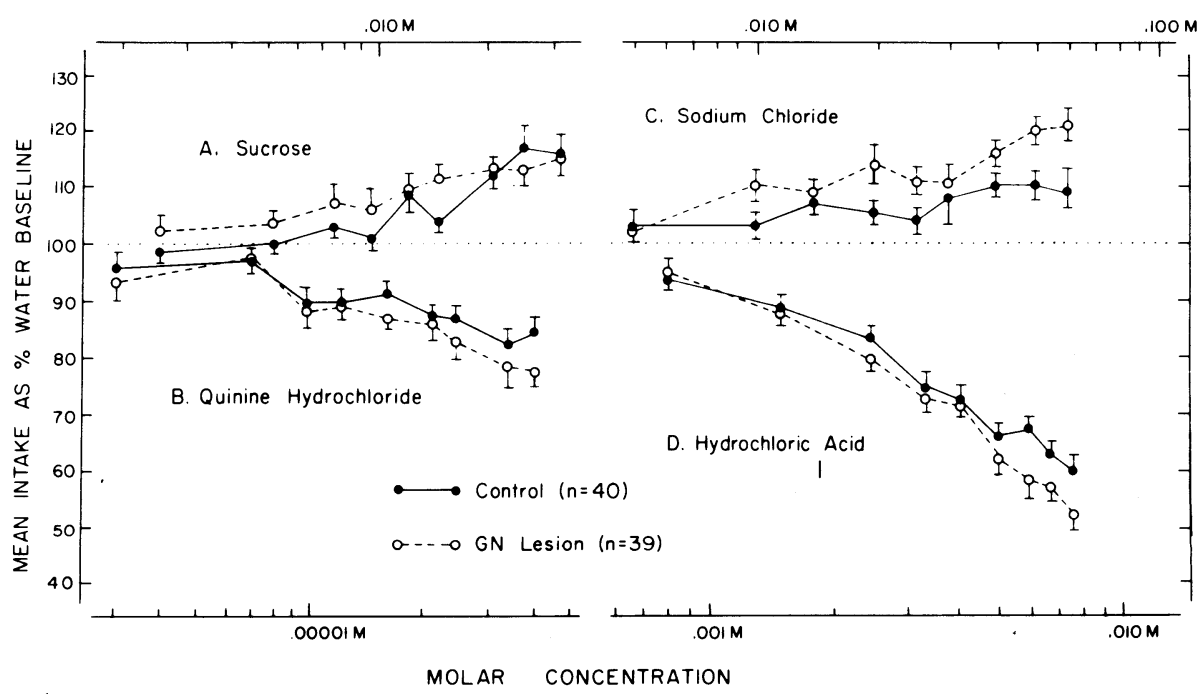

Figure 6. Threshold concentration response functions using the concentration values labeled " $\dagger$ " in Table 2. Other details are as described for Figure 4. 


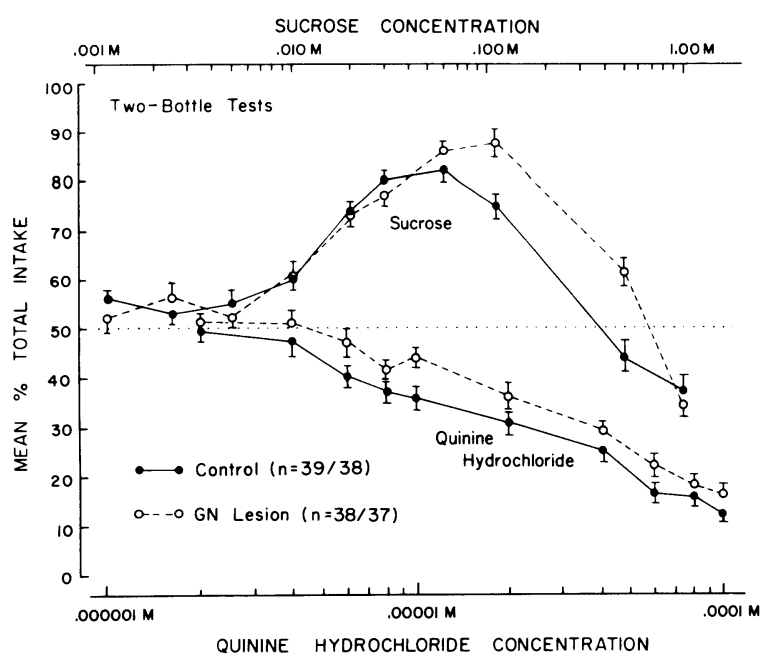

Figure 7. Two-bottle tests for sucrose and quinine hydrochloride using the concentration values labeled " $\neq$ " in Table 2. See text for how these measures differ from those presented in the previous figures.

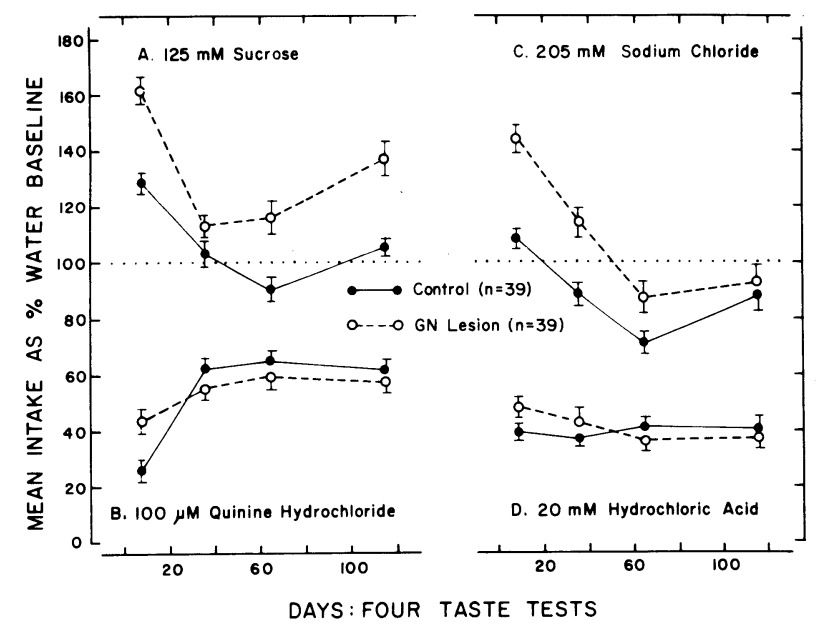

Figure 8. Four-taste tests, one-bottle, using the taste concentrations identified on the figure. See text and Table 1 for further description. In panel $B$, the quinine hydrochloride concentration is listed in micromolar units $(\mathrm{mM} \times 1,000)$.

tivity difference between normal and GN-ablated groups was observed, eventually, to dissipate (see Burton \& Benjamin, 1971).

Benjamin (1955a) had noted previously that quinine reactivity differences were not evident between normal and $\mathrm{GN}$-ablated rats when one-bottle testing procedures were used, and he was able to attribute this to the water-deprivation conditions imposed for the one-bottle, but not the two-bottle, tests (Benjamin, 1955b). He also found evidence of hypogeusia to disappear under deprivation conditions for two-bottle measures. However, the observation remains that what appeared to be a less sensitive reaction to quinine was specific to lesions of the GN area (Benjamin \& Pfaffmann, 1955), under conditions of no depriva- tion, regardless of the kind of testing procedure employed (Benjamin, 1955b). But the effect seemed to eventually disappear with experience (see Burton \& Benjamin, 1971).

It is suggested that the appearance of hypogeusia in rats lacking GN was based on subtle associative or performance factors, with normal rats perhaps being more facile at learning to anticipate mild postingestional effects of quinine consumption (Kratz \& Levitsky, 1978) as, in Benjamin's procedures, a concentration series was decreased. Such an interpretation is indirectly suggested by the results of other sensory neocortex ablation studies. For example, what would appear to be brightness threshold differences between normal rats and rats lacking visual neocortex (Lashley, 1930) diminishes with extensive training (e.g., LeVere \& Mills, 1977). Therefore, this effect may be attributed to differences in associative or performance capacities rather than to differences in basic sensory abilities. As Lashley (1935/1960) observed with regard to brightness discrimination performances of rats lacking visual neocortex, "The animal would make better than chance scores but could not be brought to the criterion of errorless performance required in the experiment . . . the majority [of the rats] were very irregular in performance, suggesting fluctuating attention rather than a genuine disturbance in vision for brightness" (p. 296). Likewise, taste criterion-threshold assessments were noted to be highly variable in early work (e.g., Benjamin \& Pfaffmann, 1955), suggesting that rats were inclined to be neglectful of the quinine stimuli, an inclination that could be overcome by increased "vigilance" (Head \& Holmes, 1911) under conditions of deprivation. This suggestion is supported by the apparent loss of reactivity to the novelty dimension of a quinine stimulus reported by Kiefer and Braun (1977), a loss that appears to be overcome after a one-trial pairing of the taste with toxicosis.

As displayed in Figures 4-8, there were no differences between control and $\mathrm{GN}$-ablated rats in acid sensitivity. We were surprised at the lack of a neophobic response to acid in normal rats because Kiefer and Braun (1977), using a slightly greater concentration $(25 \mathrm{mM}$ as compared with $20 \mathrm{mM}$ in the present study), had observed neophobia. However, other differences in procedure, beyond the stimulus intensity difference, may have masked such an effect. We note, in retrospect, that the insula ventral to the classically defined GN area (Lasiter \& Glanzman, Note 1) may be crucially involved in acid sensitivity but not necessarily in sucrose or quinine sensitivity (Kiefer, Leach, \& Braun, Note 2). It was difficult to assess the completeness of ablation of the insular cortex on the basis of our histological material. However, in 10 of the lesions, a slender band of tissue along the rhinal bank was clearly spared; this is an area which others have emphasized as being important in taste 
aversion learning (Benjamin \& Akert, 1959; Yamamoto et al., 1980; Lasiter \& Glanzman, Note 1) or taste reactivity (Benjamin \& Akert, 1959). However, we were unable to discern differences between these 10 rats and the 19 rats with lesions that clearly included the rhinal bank (but not necessarily the entire agranular insular cortex). As indicated in the anatomical discussion, the role of the insular cortex in taste sensibility remains somewhat speculative at this time.

The results of this study add detail to what has been apparent within the literature for many years. Early observations by Macht (1951) indicated that decerebrated cats rejected quinine-adulterated liver by pushing it out of their mouths with their tongues at about the same "threshold" as normal cats. Wolf, DiCara, and Braun (1970) found that rats with massive ablations of anterolateral cortex centered on GN continued to adjust $\mathrm{NaCl}$ intake appropriately in response to sodium depletion. The idea that taste acceptance or the rejection of substances placed in the mouth represents a reflex response at a most fundamental (midbrain or hindbrain) level (Grill \& Norgren, 1978b; Nowlis, 1977; Pfaffmann, Norgren, \& Grill, 1977), perhaps like the movements of the eyes in response to a moving visual field, has considerable support. Tongue responses to varying concentrations of sweet tastes in human neonates were shown to reflect a concentration sensitivity essentially similar to that displayed by adult humans using standard psychophysical measures (Nowlis, 1973; Nowlis \& Kessen, 1976). This observation in taste-naive neonates suggests a reflex basis for taste-preference responses. The possibility that such reflexes are mediated principally at the brainstorm level is supported by the observation of characteristic facial responses (the "gustofacial response') to basic taste stimuli in anencephalic human infants (Steiner, 1973). Most compelling in this regard, Grill and Norgren (1978b) found that decerebrated rats display discriminably characteristic sequences of facial responses and gestures (mimetic responses) to basic taste stimuli.

If the entire forebrain can be eliminated, leaving an animal that remains differentially responsive to basic taste stimuli as indicated by behavioral criteria, then the gustatory neocortex obviously is not necessary. However, it may nonetheless contribute to modulating such responsiveness on the basis of experience, perhaps by recruiting fundamental acceptance and rejection reflexes in the service of changing the intake of specific taste stimuli (Nowlis, 1977; Pfaffmann et al., 1977). As pointed out by Pfaffmann et al. (1977), this "reflexological" perspective is supported by the observation that when intact rats learn a conditioned taste aversion to normally highly palatable sucrose, their behavioral pattern of rejection of the sucrose mimics the observed unlearned pattern of rejection to unpalatable quinine solutions (Grill, 1975). Accordingly, the question addressed in the fol- lowing section of this review concerns the involvement of the GN in the rat's capacity to adapt its responses to basic taste stimuli signaling imminent malaise.

\section{TASTE LEARNING}

To establish the perspective of the following sections of this review, it is acknowledged that the major research activities of the senior author have concerned the role of the sensory neocortex in cognitive processes. The dominant heuristic orientation to this interest has been provided by classical hierarchical theory (Jackson, 1884/1958; Pavlov, 1927/1960), which views basic reflexes as adaptively modulated via superimposed control from "higher level" (e.g., cortical) processes. Initial interest in gustatory neocortical function developed from questions concerning the degree to which generalizations derived from behavioral studies of visual, auditory, and somatosensory neocortices might be applicable to gustatory regions. The principal advantage of studying gustatory processes from a hierarchical perspective is that taste stimuli have a powerful and enduring impact on relevant behavior without prior training (e.g., Young, 1966). Rats display characteristic concentration response functions to representative tastes from each of the four major taste classifications, as discussed in the previous section. Therefore, assessments of the abilities of rats to respond differentially to a particular taste stimulus can be based upon solution consumption relative to water, although potential complications introduced by the influence of postingestional factors (Pfaffmann, 1969) and confounded odor factors (e.g., Benjamin, 1960; S. D. Miller \& Erickson, 1966) must be addressed.

The pronounced and discriminable effects of tastes on simple drinking behavior, as compared with reflexive behaviors that might be affected or provoked by visual, auditory, or somatosensory stimulation, identify a second advantage of studying brain mechanisms of gustatory processes. Whereas one may use the same dependent measure (amount of a taste solution consumed) for assessments of both learned and reflexive taste responses, this is relatively difficult to do in studies of other sensory systems. The unlearned responses elicited by other sensory modes typically are not obvious or differential (e.g., the naive rat's responses to different pitches), or the responses quickly habituate (e.g., startle responses). In addition, with other sensory modes, a simple preference response might be eliminated following ablation of relevant sensory neocortex while the associative potential for the same class of stimulus, though impaired, will be spared (e.g., depth discrimination; Braun, Lundy, \& McCarthy, 1970). Taste stimuli, on the other hand, retain a clear impact on simple drinking and choice behavior when gustatory neocortex is ablated (see 
previous discussion), and this provides a distinct baseline against which to assess the influence of $\mathrm{GN}$ ablation upon associative processes.

Classical assessments of the effects of sensory neocortex ablation, from Munk (1890) through Lashley (e.g., 1942), generally used specific training procedures to obtain estimates of intramodal perceptual capacities. Because of this, potentially separable reflexive, perceptual, and associative capacities tended to be confounded in those studies. Thus, while Lashley's (1930) early data indicated that rats lacking visual neocortex suffered basic sensory deficits in perceiving brightness, the deficits appear to have been related to associative or performance dimensions of the learning task that was used by Lashley to assess brightness discrimination (Cooper, Freeman, \& Pinel, 1967; LeVere \& Mills, 1977). There were, however, exceptions in the literature to this kind of methodological confounding. For example, K. U. Smith (1937) assessed optokinetic nystagmus responses in cats to revolving stripes following extensive posterior cortical ablations and found that such responses did not appear to be degraded relative to those of normal animals. Thus, cats with such cortical lesions appeared capable of responding to contour information by this measure, despite profound deficiencies in learning visual pattern/form discriminations (K. U. Smith, 1938). These results indicated that the associative or performance debility in the learning situation was not based on blindness to visual edges (see Braun, 1978, and Spear, 1979, for a more detailed analysis of this problem). Likewise, as we shall discuss later, associative deficiencies for taste stimuli in rats lacking $\mathrm{GN}$ are not based on ageusia. $^{2}$

The data on basic differential sensitivity to taste stimuli, as reviewed previously, is consistent with a fundamental generalization concerning sensory neocortex function per se that is apparent from examining the literature on the effects of specific sensory neocortex ablations in a number of mammalian species: These preparations are not behaviorally insensitive to fundamental stimuli in the sensory mode relevant to the missing sensory neocortex. This is where one must begin when attempting to determine the nature of the involvement of sensory neocortex in perceptual behavior. Rats lacking visual neocortex, for example, display visual placing responses (Braun, 1966) and readily learn brightness (Lashley, 1935) and, with difficulty, depth discriminations (Braun et al., 1970); they can also learn some two-dimensional pattern discrimination problems, and this general observation is true for number of species (see Spear, 1979). Likewise, rats lacking somatosensory neocortex learn roughness discrimination habits (e.g., Finger, Marshak, Cohen, Scheff, Trace, \& Niemand, 1971; Zubek, 1951) and rats lacking auditory neocortex re- main capable of learning associative responses to tones (French, 1942).

This generalization concerning sensory neocortical function does not imply that the relevant sensory cortices are uninvolved in these habits; it indicates only that the brain areas are not necessary for fundamental detection and discrimination of appropriate stimuli. Thus, rats lacking visual neocortex can acquire, or reacquire, basic visual habits, but with reduced efficiency relative to normal rats (e.g., Horel, Bettinger, Royce, \& Meyer, 1966). If deficits in learning specific to both a sensory mode and a neocortical subarea are a general consequence of sensory neocortical damage, then it is the nature of these deficiencies (the experimental conditions under which they may be magnified or decreased) that must be clarified.

Originally, we anticipated the possibility that different kinds of behavioral results might be associated with GN ablation because of the unusual nature of taste aversion learning, viz., the long CS-US delays that are possible (Revusky \& Garcia, 1970), the essentially visceral nature of the US (Garcia \& Ervin, 1968), and the clear hedonic reactions exhibited by GNablated rats to basic taste stimuli. In addition, at the time we began our studies it was becoming increasingly evident that taste aversion learning resisted interference by various influences (e.g., anesthetization, cortical spreading depression) which profoundly disrupt other kinds of learning (e.g., Best \& Zuckerman, 1971; Nachman, 1970; Roll \& Smith, 1972). However, as we show below, the behavioral effects of GN ablation proved to be essentially similar to what one would expect on the basis of studies of other sensory neocortical areas.

\section{Initial Experiments}

Our original studies were designed to encompass a number of reasonable alternatives regarding possible relationships between GN and taste aversion learning. We wished to differentiate nonspecific unconditioned stimulus (US) effects (e.g., sensitization) from discriminatively specific taste-illness associations, to explore the associative salience of taste conditional stimuli (CSs) representing both negative and positive hedonic dimensions, and to distinguish learning deficiencies stemming from problems of US processing from problems of CS processing. We also controlled for the possibility of nonspecific deficiencies produced by cortical damage per se.

Quinine hydrochloride $(.1 \mathrm{mM})$ and sodium saccharin $(4.8 \mathrm{mM})$ were initially selected as conditional stimuli because, in pilot studies using one-bottle tests, they had been clearly detectable, relative to water, by rats lacking GN. Cyclophosphamide injections served as the US because we had found, in pilot work, that robust, one-trial, discriminatively specific taste aversions could be produced with this US in nor- 
mal rats when it was paired with one of two hedonically matched taste stimuli. Conditional taste stimuli were introduced to rats that were on a drinking schedule of $15 \mathrm{~min}$ of access to fluids (one-bottle) every $12 \mathrm{~h}$, followed on the first presentation by injections of cyclophosphamide $(100 \mathrm{mg} / \mathrm{kg}$, ip) within $1 \mathrm{~min}$ of completion of the drinking period (Braun et al., 1972).

Following the one-trial training procedure, the effectiveness of the conditioning procedure was measured over test trials in extinction using the following procedure: The paired taste, the unpaired taste, and water were presented to all rats in an order that was balanced both within and between groups for any triad of consecutive presentations (called a "cycle"). Three cycles of the tastes and water were presented in extinction. There were two major groups of rats in the study, normal and GN-ablated groups; within each group were subgroups that had had solutions of saccharin, quinine, or water paired with the drug on the training trial. There was also a subgroup that received water paired with control injections of physiological saline. In addition, a group with dorsomedial neocortex lesions equivalent in extent to the GN lesions received saccharin paired with cyclophosphamide injections.

With this design, we expected to characterize the effects of the training trial within the $\mathrm{GN}$-ablated and normal groups, for both taste stimuli, according to the kinds of outcomes portrayed ideally in Figure 9. As indicated in Table 3, outcome A characterized the results for normal rats trained to avoid either the quinine or saccharin stimulus: a discriminatively specific learned aversion to the taste cue that had been paired with the drug, plus a clear nonspecific drug effect (a generalized reduction of all fluid consumption). This outcome also characterizes the results for the lesion control group and for the group lacking GN that had been trained to avoid quinine. This latter group could not be differentiated statistically from its normal counterpart; thus, we concluded that the quinine CS and the US were clearly effective in rats lacking GN. The conclusion regarding the US was supported by the observation that all drug-injected GN groups displayed significant and equivalent nonspecific partial reductions of total fluid intake relative to the nondrug control groups. The nonspecific effect of the drug in groups lacking GN was virtually the same magnitude as displayed by the drug-injected normal groups.

The most interesting finding was that rats lacking GN did not acquire an aversion to the $4.8-\mathrm{mM}$ saccharin stimulus, but showed only a nonspecific drug effect. The nondrugged control rats with GN lesions, however, drank significantly more of the saccharin solution than water; this confirmed that the saccharin solution was detectable by the brain-damaged rats. Therefore, with this training paradigm, we had

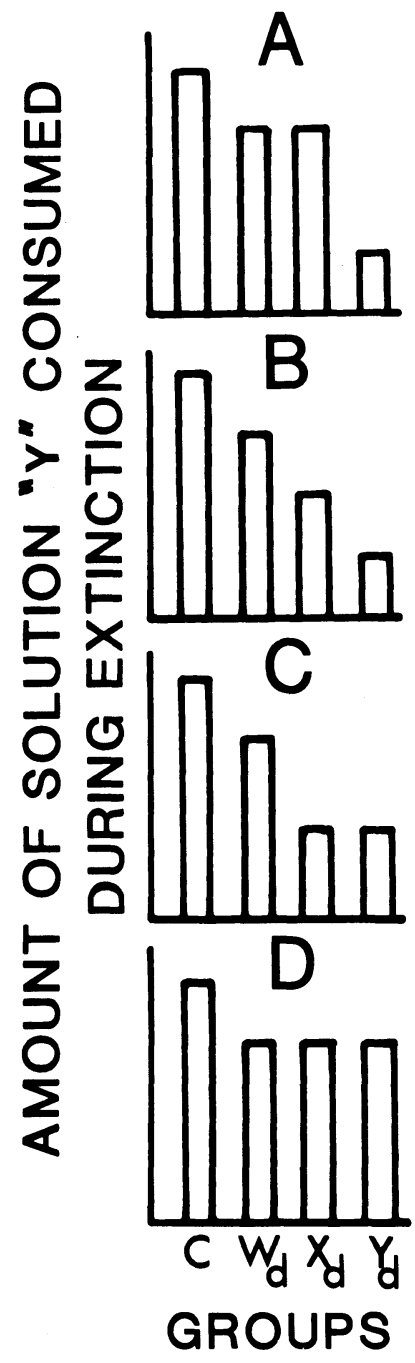

Figure 9. Some potential idealized outcomes for experiments designed to assess the discriminative conditionability of tastesolution CS paired with a malaise-inducing drug US. Portrayed are relative amounts consumed of a specific taste solution ( $Y$ ) by four groups of rats after the following treatments: Group $\mathrm{C}$-Control group; water paired with saline injection. Group $\mathbf{W}_{\mathrm{d}}-$ Control group for nonspecific drug effects; water paired with drug injection. Group $X_{d}$-Taste $X$ paired with drug injection. Group $Y_{d}-$ Taste $Y$ paired with drug injection. Panel A: Discriminatively specific learned aversion to taste $Y$ plus a nonspecific effect of the drug US on fluid consumption. Panel B: Discriminatively specific learned aversion to taste $Y$, plus significant generalization to taste $Y$, by Group $x_{d}$, plus a nonspecific drug effect. Panel C: Nonspecific aversion to taste $Y$ produced by pairing either taste stimulus with the drug, plus a nonspecific drug effect. Panel D: No taste effect. Nonspecific drug effect. Note: Nonspecific drug effects were not always obtained in the experiments described in the text, and a Group $C$ was not included in all experiments. In addition, the statistical analyses of the summarized experiments considered both between-group comparisons, as above, for taste $\dot{x}$, taste $Y$, and water consumption following training, and withingroup comparisons. Consumption of each solution was measured for every rat in each study for analyses of paired-taste, unpairedtaste, and water consumption following training. The idealized outcomes portrayed in this figure essentially characterize the outcomes obtained in experiments summarized in Table 3 as determined by the statistical results of at least two convergent analyses. 
Table 3

Summary of Stimuli and Interpretations of Outcomes for Eight Conditioned Taste Aversion Experiments Comparing Normal (N) and GN-Ablated (GN) Rats

\begin{tabular}{|c|c|c|c|c|c|}
\hline \multirow[b]{2}{*}{ Experiment } & \multirow[b]{2}{*}{ CS } & \multirow{2}{*}{$\begin{array}{l}\text { CS Concentration } \\
\text { (in Millimoles) }\end{array}$} & \multirow{2}{*}{$\begin{array}{l}\text { CS-US } \\
\text { Delay? }\end{array}$} & \multicolumn{2}{|c|}{ Group } \\
\hline & & & & $\mathbf{N}$ & GN \\
\hline Braun et al., 1972 & $\begin{array}{l}\text { Sodium Saccharin } \\
\text { Quinine } \mathrm{HCl}\end{array}$ & $\begin{array}{r}4.8 \\
.1\end{array}$ & $\begin{array}{l}\text { No } \\
\text { No }\end{array}$ & $\begin{array}{l}\mathbf{A} \\
\mathbf{A}\end{array}$ & $\begin{array}{l}\text { D } \\
\text { A }\end{array}$ \\
\hline \multicolumn{6}{|l|}{ Lorden, 1976} \\
\hline Experiment 1 & $\begin{array}{l}\text { Sucrose } \\
\mathrm{NaCl}\end{array}$ & $\begin{array}{l}144.5 \\
154.9\end{array}$ & $\begin{array}{l}\text { No } \\
\text { No }\end{array}$ & $\begin{array}{l}\mathbf{A} \\
\mathbf{A}\end{array}$ & $\begin{array}{l}\text { D } \\
\text { A }\end{array}$ \\
\hline Experiment 2 & $\begin{array}{l}\text { Quinine } \mathrm{HCl} \\
\mathrm{HCl}\end{array}$ & $\begin{array}{r}.1 \\
25.1\end{array}$ & $\begin{array}{l}\text { No } \\
\text { No }\end{array}$ & $\begin{array}{l}\mathbf{A} \\
\mathbf{A}\end{array}$ & $\begin{array}{l}\text { B } \\
\text { B }\end{array}$ \\
\hline Experiment 3 & $\begin{array}{l}\text { Sucrose } \\
\mathrm{NaCl}\end{array}$ & $\begin{array}{l}144.5 \\
154.9\end{array}$ & $\begin{array}{l}\text { Yes* } \\
\text { Yes* }\end{array}$ & $\begin{array}{l}\mathbf{A} \\
\mathbf{A}\end{array}$ & $\begin{array}{l}\mathrm{C} ? \\
\mathrm{C}\end{array}$ \\
\hline Experiment 4 & $\begin{array}{l}\text { Quinine } \mathrm{HCl} \\
\mathrm{HCl}\end{array}$ & $\begin{array}{r}.1 \\
25.1\end{array}$ & $\begin{array}{l}\text { Yes* } \\
\text { Yes* }\end{array}$ & $\begin{array}{l}\text { A } \\
\text { A }\end{array}$ & $\begin{array}{l}\text { B } \\
\text { C }\end{array}$ \\
\hline Experiment 5 & $\begin{array}{l}\text { Sucrose } \\
\text { Quinine } \mathrm{HCl}\end{array}$ & $\begin{array}{r}1000 \\
.032\end{array}$ & $\begin{array}{l}\text { No } \\
\text { No }\end{array}$ & $\begin{array}{l}\mathrm{A} \\
\mathrm{B} ?\end{array}$ & $\begin{array}{l}\text { A } \\
\text { D }\end{array}$ \\
\hline Braun \& Rosenthal, 1976 & $\begin{array}{l}\text { Sodium Saccharin } \\
\text { Quinine } \mathrm{HCl}\end{array}$ & $\begin{array}{r}4.8 \\
.1\end{array}$ & $\begin{array}{l}\text { Yes* } \\
\text { Yes* }\end{array}$ & $\begin{array}{l}\text { D } \\
\text { A }\end{array}$ & \\
\hline Kiefer \& Braun, 1979† & $\begin{array}{l}\text { Sucrose } \\
\mathrm{NaCl}\end{array}$ & $\begin{array}{l}146 \\
153\end{array}$ & $\begin{array}{l}\text { No } \\
\text { No }\end{array}$ & $\begin{array}{l}\mathbf{A} \\
\mathbf{A}\end{array}$ & $\begin{array}{l}\text { B } \\
\text { B }\end{array}$ \\
\hline
\end{tabular}

Note-The interpretations listed under "Group" correspond to the idealized outcomes partially portrayed in Figure 9. This is intended to be a general comparative summary of the results of the eight experiments for purposes of simplifying the present discussion. Compared with the analysis in the original studies (identified under "Experiment," in the first column), the present interpretations are coarse, and two of them, labeled "?," are somewhat uncertain. Although outcome " $A$ " remained the best interpretation of normal performance under the CS-US delay condition, it should be noted that the taste aversions acquired under this condition were generally weaker (less resistant to extinction) than those established under the no-delay conditions. The first seven experiments employed a one-trial training paradigm, with intraperitoneal injections of cyclophosphamide serving as the US. The Kiefer and Braun (1979) experiment used repeated training trials, with apomorphine hydrochloride as the US. All of the experiments used a discrimination paradigm, as indicated, and in five of the experiments (Lorden, 1976, Experiments 1-4, and Kiefer \& Braun, 1979), the two taste stimuli were approximately matched by hedonic response criteria (e.g., see Figure 4). The original studies should be consulted for more details of procedure and results. $\quad{ }^{*} 6 \mathrm{~h}$. $\quad$ †Repeated trials.

found a clear instance of a detectable taste cue that was not conditionable for rats lacking GN. However, the saccharin cue was readily conditionable for normal rats and for rats with control lesions (Braun et al., 1972).

Subsequent work by Divac, Gade, and Wikmark (1975) indirectly suggested the specificity of involvement of the GN area in taste aversion learning by showing no effect of orbital frontal lesions on such learning. However, Hankins, Garcia, \& Rusiniak (1974) reported a disruption of taste aversion learning by frontal lesions that were considerably smaller than those described by Divac et al. (1975). Throughout our own studies, we have repeatedly found clear dissociations between the effects of cortical lesions centered on the GN area and the effects of lesions outside of the GN area on taste learning and retention.

We speculated that the change in the "salience" (Kalat \& Rozin, 1970), or conditionability, of the saccharin cue, without concomitant changes in detectability relative to water, might be a common effect of GN lesions across taste qualities, an effect which may not have been observed for the quinine stimulus in this first study because of a floor effect (Braun et al., 1972). As a basis for follow-up studies, it was hypothesized that there were two kinds of relatively independent thresholds to consider for taste stimuli: a preference-aversion, or reactive, threshold, and a conditionability, or associative salience, threshold. This idea was based partly on reports showing that the potential associative strength of taste CSs could not readily be predicted from the relative preferences normal rats displayed to several flavor or taste stimuli (Kalat \& Rozin, 1970; Tapper \& Halpern, 1968). It was hypothesized further that GN ablation selectively disrupts associative salience thresholds for taste stimuli without necessarily disrupting detection thresholds (Braun \& Rosenthal, 1976); that is, the systems underlying associability and detectability of the same stimuli could be viewed as being dissociated by the GN lesion.

Braun and Rosenthal (1976) found that a procedure known to reduce the associative potential of normal rats for tastes, the imposition of a very long CS-US interval (e.g., Revusky \& Garcia, 1970; J. C. Smith \& Roll, 1967), produced results for normal rats that were essentially identical to those reported by Braun et al. (1972) for rats lacking GN (see Table 3). It was therefore concluded that the Braun et al. (1972) finding of a salience difference between .1-mM-quinine 
and 4.8-mM-saccharin stimuli was probably due to the unmasking, by GN ablation, of a normal salience difference between these stimuli. In other words, the effect did "not appear to represent a unique lesionproduced change in the relative salience of the two stimuli"' (Braun \& Rosenthal, 1976, p. 350). Furthermore, the finding by Hankins et al. (1974) that rats with partial lesions of the GN could learn to avoid $4.8 \mathrm{mM}$ saccharin when repeated training trials were employed, using $\mathrm{LiCl}$ intubation as the US, suggested that such rats were not absolutely deficient, but only relatively deficient, for the saccharin CS. However, the Hankins et al. (1974) results were difficult to interpret, because no provision for assessing nonspecific drug effects or discriminative specificity was included in their analysis. In addition, their lesions were considerably smaller than ours, often not encompassing the entire GN area (approximately $75 \%$ of the total GN area; see Hankins et al., 1974).

In order to examine convincingly the hypothesis concerning the role of GN in associative thresholds for tastes, other hypotheses suggested by the Braun et al. (1972) results first had to be considered: Perhaps the associative deficit in rats lacking GN was peculiar to saccharin stimuli, to sweet stimuli, or to positively hedonic stimuli in general. We reasoned, for example, that acquisition of an aversion to positively hedonic stimuli might require a more complex underlying brain mechanism (reversal of a reflexive preference) than acquisition of aversions to negatively hedonic stimuli (facilitation of a reflexive aversion).

A comprehensive study by Lorden (1976) revealed that $\mathrm{GN}$-ablated rats displayed clear associative deficiencies, similar in magnitude to the saccharin deficiency described by Braun et al. (1972), for clearly detectable sucrose and quinine hydrochloride stimuli (see Table 3; Lorden, 1976, Experiments 1 and 5). The latter result indicated that, by lowering the concentration of quinine that had been used previously by Braun et al. (1972), a concentration could be found at which dissociation between detectability and associability of quinine could be observed in rats lacking GN relative to the performance of normal rats. Therefore, the Braun et al. (1972) result was not specific to a particular class of taste stimuli.

As indicated in Table 3, when hedonically equivalent quinine and $\mathrm{HCl}$ stimuli were used in our discrimination paradigm (Lorden, 1976, Experiment 2), learned aversions to these cues by $\mathrm{GN}$-ablated rats were not as discriminatively precise as those observed for normal rats. In addition, imposing a 6-h delay between presentation of the taste CS and administration of the US did not prevent normal rats from learning discriminatively specific aversions to 145 -mM-sucrose or $155-\mathrm{mM}-\mathrm{NaCl}$ solutions, but this obliterated development of a learned aversion to these stimuli in GN-ablated rats (Lorden, 1976, Experiment 3): Despite the training trial, these rats drank signifi- cantly, and equivalently, more of the salt and sucrose taste solutions than of water (see Lorden, 1976, Figure 4). Likewise, the discriminative specificity of a learned aversion to $25 \mathrm{mM} \mathrm{HCl}$ was lost by rats lacking GN under the CS-US delay condition (Lorden, 1976, Experiment 4). This disruption of the maintenance of a trace of a taste by GN lesions under CS-US delay conditions was consistent with the results of a cortical spreading depression study reported by Burešova and Bureš (1973).

Despite the apparent generality of the disruption of associative salience across the four basic taste qualities following GN lesions, Lorden's results also suggested that some taste qualities might be disrupted more than others. The overall pattern of results suggested to Lorden that, while it was relatively difficult to find specific conditions under which the associative potential of quinine stimuli might be disrupted, no condition was found for sucrose which led to equivalent results for normal and $\mathrm{GN}$-ablated rats. For example, although both groups displayed specific learned aversions to a very strong sucrose solution $(1 \mathrm{M})$, when it was discriminatively assessed against a mild quinine solution (see Table 3, Lorden, 1976, Experiment 5), there was a substantial difference between the two groups in the magnitude of the aversion: normal rats drank virtually none of the sucrose in extinction, whereas rats lacking GN drank a mean of over $5 \mathrm{ml}$ per test trial (see Lorden, 1976, Figure 6). It is likely that evaluation of the associative salience of the strong sucrose solution against a more similar stimulus (e.g., a highly preferred $\mathrm{NaCl}$ solution) would have additionally revealed disrupted discriminative specificity.

\section{Discriminative Salience}

Confirming Lorden's general finding of disrupted discriminability, Kiefer and Braun (1979) found that while rats lacking $\mathrm{GN}$ would eventually learn to discriminate $146 \mathrm{mM}$ sucrose from $153 \mathrm{mM} \mathrm{NaCl}$ when repeated training trials were used with apomorphine hydrochloride as the US, these rats displayed abnormal generalization between the two cues (Table 3). On the basis of these and Lorden's results, it was hypothesized that the discrimination of highly similar taste cues within a qualitative class of taste stimuli should be very severely disrupted by GN lesions. A thesis by Phillips (1977) tested this possibility using equimolar $\mathrm{NaCl}$ and $\mathrm{LiCl}$ stimuli, with the US being provided by the toxic consequences of ingesting the $\mathrm{LiCl}$ solutions. These consequences become associated with the taste of $\mathrm{LiCl}$ in this paradigm (D. F. Smith \& Balagura, 1969) and generalize almost completely to equimolar $\mathrm{NaCl}$ ( $\mathrm{Nachman}, 1963)$, but the two salts can be discriminated eventually by normal rats following extensive experience (e.g., Fregly, 1958; Kiefer, 1978).

Phillips trained extensively two groups of rats, 12 normal and 12 lacking GN, to avoid drinking $120 \mathrm{mM}$ 
LiCl. She then conducted a series of generalization tests to $\mathrm{NaCl}$ stimuli in extinction. Following the generalization testing, the rats were retrained to avoid $\mathrm{LiCl}$ and then subjected to discrimination training using $120 \mathrm{mM} \mathrm{NaCl}$ as the discriminative stimulus and a one-bottle training procedure similar to that used by Braun et al. (1972). So, at the time of discrimination training, the rats had received. extensive experience with both $\mathrm{LiCl}$ and $\mathrm{NaCl}$, but only the $\mathrm{LiCl}$ had been accompanied by toxicosis.

The results of the discrimination training test were initially surprising (see Figure 10). It appeared that the rats lacking $\mathrm{GN}$ learned the $\mathrm{NaCl}-\mathrm{LiCl}$ discrimination with more alacrity than did normal rats. Although generalization was evident for both groups, asymptotic performance was acquired more readily by the GN-ablated group. Oddly, however, the GN rats continued to drink 1 to $3 \mathrm{ml}$ of $\mathrm{LiCl}$ every time it was presented, reliably more so than normal rats. This suggested discrimination between the solutions on the basis of early-onset postingestional feedback.

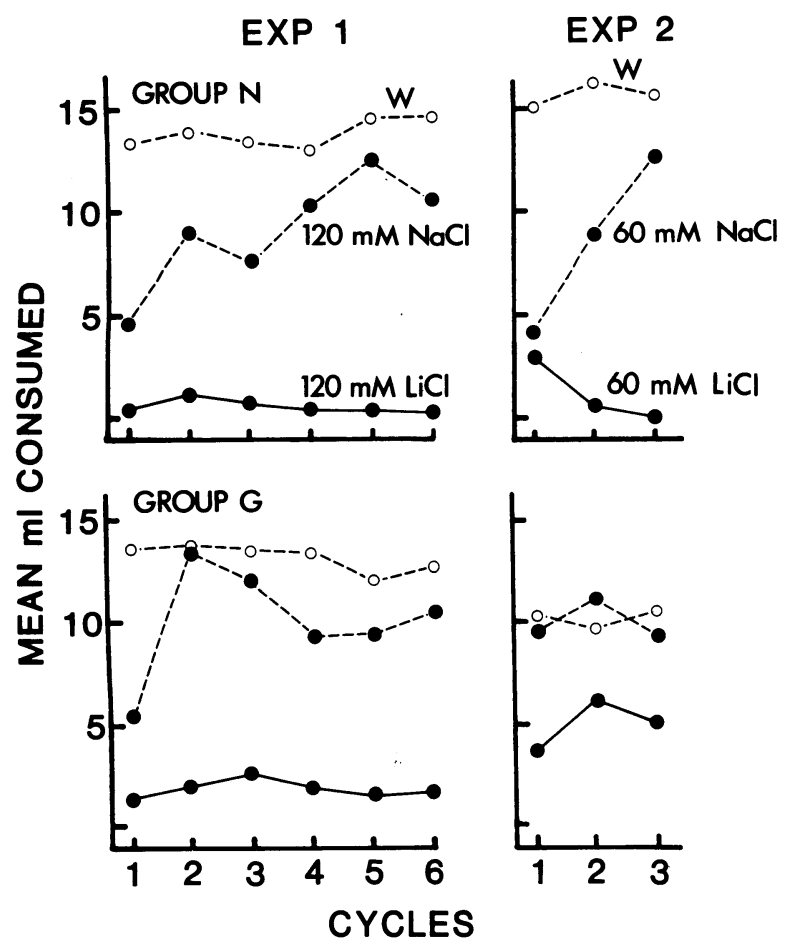

Figure 10. Discrimination training results for equimolar solutions of $\mathrm{NaCl}$ and $\mathrm{LiCl}$ in two experiments for normal (Group $\mathrm{N}$ ) and GN-ablated (Group G) rats. Mean amounts consumed of equimolar $\mathrm{LiCl}$ and $\mathrm{NaCl}$ solutions and distilled water as a function of training cycles. The rats in these experiments all had had considerable experience with various concentrations of both taste solutions in prior experimental manipulations. Experiment $1 \mathrm{em}-$ ployed $120 \mathrm{mM}$ salt solutions and Experiment 2, $60 \mathrm{mM}$ salt solutions, for discriminative training. The top two panels summarize the performance of the normal groups, and the bottom two panels, that of the GN-ablated groups. See the text for more details of these experiments. (Redrawn from Phillips, 1977).
That is, operated rats may have stopped drinking salty solutions when they began to detect negative postingestional consequences, but would continue if no such consequences occurred. The normal rats, on the other hand, appeared to have learned the discrimination on the basis of taste cues. We hypothesized, therefore, that reducing the concentration of the salt stimuli by half, to $60 \mathrm{mM}$, should result in a marked increase of $\mathrm{LiCl}$ intake by rats lacking $\mathrm{GN}$. However, this occurred to us only after having sacrificed the rats used in this experiment.

Phillips (1977) conducted a second study designed to replicate certain selected features of the first. All of the rats in this study were first exposed to extensive avoidance training using $120 \mathrm{mM} \mathrm{LiCl}$, and were then presented with a series of $\mathrm{NaCl}$ generalization tests during extinction. They were next trained to avoid $60 \mathrm{mM} \mathrm{LiCl}$ presented alone, and finally subjected to discrimination training using $60-\mathrm{mM} \mathrm{LiCl}$ and $\mathrm{NaCl}$ solutions. The results of the discrimination training were as predicted. Normal rats displayed classic, diverging discrimination functions over three cycles of training, with $\mathrm{LiCl}$ consumption dropping to zero and $\mathrm{NaCl}$ consumption approaching the level observed for water consumption. On the other hand, the functions for rats lacking GN remained flat: these rats drank approximately $10 \mathrm{ml}$ of $\mathrm{NaCl}$ and $5 \mathrm{ml}$ of $\mathrm{LiCl}$ solutions on each of the three cycles of testing (see Figure 10). This suggests that the extensive prior experience with salt solutions, some of which resulted in malaise, led to the two groups of rats' using different strategies for discriminating the solutions. The normal rats appeared to be using taste cues as a basis for differentiation, because after a few licks of the drinking tube they drank virtually none of the $\mathrm{LiCl}$ by the third cycle. In contrast, rats lacking GN appeared to have developed a strategy using postingestional cues. This result is reminiscent of the "tricks" (Sperry, 1947) used by brain-damaged animals to circumvent neurological deficiencies in regaining capacities to perform specific tasks (e.g., Goldberger, 1974).

In Phillips' experiments, taste differences between $\mathrm{LiCl}$ and $\mathrm{NaCl}$ did not appear to be salient for rats lacking GN, but postingestional consequences remained discriminable and served as a basis for distinguishing between the two chemical stimuli. In this regard, it is interesting to note that on the first trial the normal rats stopped consuming the $60-\mathrm{mM}-\mathrm{LiCl}$ solution after having drunk about $3 \mathrm{ml}$ and rats lacking GN continued to drink about 4 to $5 \mathrm{ml}$ throughout testing. It should be noted also that $60 \mathrm{mM} \mathrm{NaCl}$ is well within the detectable range of concentrations for rats lacking GN (see Figure 3).

Thus, at this point in the research program, two major effects of GN lesions on the acquisition of avoidance responses to taste stimuli could be discerned. Conditioning was less efficient than normal 
for all basic taste qualities, and the discriminative grain of acquired taste aversions was less precise. The degree of the observable deficiency in rats lacking GN, relative to normal rats, could be manipulated by (1) changing stimulus concentration, (2) using a repeated trials training paradigm instead of the singletrial procedure with which we had begun, (3) increasing the delay between exposures to the CS and US, and (4) decreasing the discriminability of paired and unpaired taste stimuli. These results, in conjunction with the data summarized in the preceding section of this paper, support the hypothesis that the GN normally contributes to the associative, discriminative salience of taste stimuli.

We continue to believe that a parsimonious explanation for these effects of GN ablation is that the lesion causes an increase in the associative taste thresholds (salience) for otherwise detectable taste stimuli. As observed by Lorden (1976), it seems that, in order to be conditionable, taste stimuli have to be more intense for rats lacking GN than for normal rats.

\section{Taste Novelty and Stimulus Intensity Dynamism}

Braun and Rosenthal (1976) observed that, in the original acquisition studies (Braun et al., 1972; Lorden, 1976), the novelty and intensity dimensions of the taste CSs had been confounded. "Novelty" is a behaviorally relevant dimension of a stimulus that can have a significant impact on its conditionability (see Corey, 1978). Rats tend to be suspicious of, or "neophobic" toward, flavors that they have not experienced (see Domjan, 1980). Revusky and Bedarf (1967) found that when rats were given both a novel and a familiar food prior to a malaise-inducing radiation treatment, the rats subsequently rejected the novel food even if the familiar food had been presented closer in time to the radiation treatment. Kalat (1974) demonstrated that the novelty of a taste cue could override intensity as a potent determinant of associative salience.

Because the effects of both novelty and intensity increase as a function of increasing taste concentration, becoming increasingly different from "safe and familiar" water (Kalat \& Rozin, 1973), we wished to selectively assess the role of "novelty" in the acquisition impairments that we had observed in rats lacking GN (Kiefer \& Braun, 1977). Using a balanced design, normal and operated rats were subjected to a series of familiarization trials with either $.1 \mathrm{mM}$ quinine hydrochloride or $25 \mathrm{mM} \mathrm{HCl}$ taste stimuli. Subsequently, the familiarization groups were subdivided into groups that were trained, using a repeated trials procedure with apomorphine hydrochloride as the US, to avoid either the novel or the familiar taste cue. The results were clear: Rats lacking GN did not display neophobia toward the initial presentations of the taste cues during familiarization, whereas normal rats drank significantly less on the initial presentation than on the fourth familiarization presentation. In addition, while both normal and operated rats learned discriminatively specific aversions to the taste cue paired with the drug, rats lacking GN did not learn to avoid the novel taste more rapidly than they did the familiar one (see Figure 11). It therefore appeared that the operated rats did not distinguish novel from familiar taste cues, that, in fact, they responded as though both tastes were familiar.

Figure 11 shows that the first training trial (Trial 0) appears to have had no obvious effect on consumption of the paired taste as measured on the second trial for normal rats trained to a familiar CS. Similarly, consumption of neither the novel nor the familiar tastes was reduced following the first CS-US pairing in rats lacking GN. In contrast, consumption of the novel taste by normal rats was significantly reduced after the first training trial. It is as if the first training trial sensitizes a rat to a taste that has been rendered "safe" as a function of prior inconsequential exposure to it, and, although salient, the taste is initially neglected (Kalat \& Rozin, 1973). But, once the potential biological importance of the cue is established (first trial), significant reduction of consumption occurs during the second trial. It would appear that the mechanism for producing stimulusspecific neglect of a taste cue on the basis of incon-

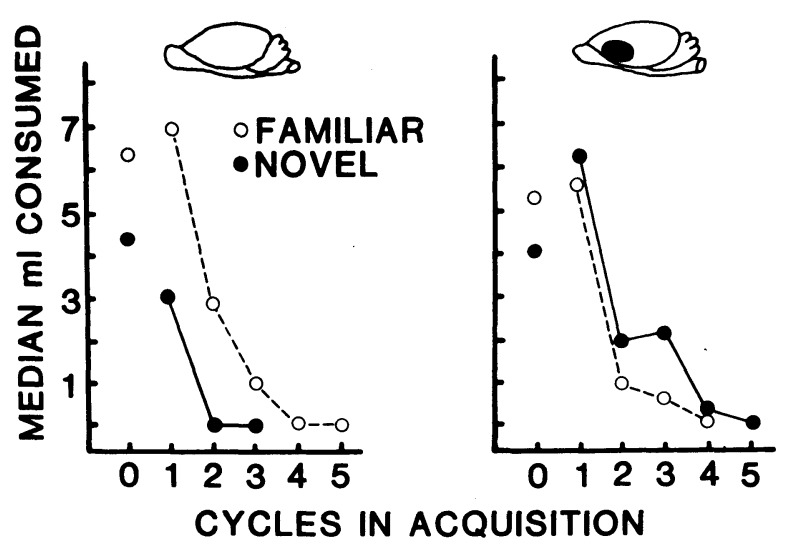

Figurre 11. Median milliliters consumed of taste solutions that were either familiar or novel by two groups of normal rats (left panel) and by two groups of $\mathrm{GN}$-ablated rats (right panel) as a function of repeated training trials. Each function represents a group of 12 rats; half of each group was trained to avoid $.1 \mathrm{mM}$ quinine hydrochloride, and the other half, to avoid $25 \mathrm{mM} \mathrm{HCl}$. These two taste solutions are approximately hedonically equivalent (see Figure 4). Each "familiar" group had experienced the taste to be paired four times before the conditioning trials began. Each "novel" group had experienced the other taste prior to conditioning using a novel (unexperienced) CS. Cycle " $O$ "' represents consumption during the initial training trial prior to experiencing the US (ip injection of apomorphine hydrochloride) for the first time. The only group showing significantly decreased consumption of the conditional taste solution on the first training cycle after the initial training trial was the normal group for which the taste stimulus was novel. (Redrawn for the top panels in Figure 2 of Kiefer \& Braun, 1977). 
sequential exposures is missing in rats that lack GN: these rats appear to be initially neglectful of both familiar and novel taste stimuli at a potential associative level. On the basis of this lack of differential reactivity to familiar and novel tastes, Kiefer and Braun (1977) proposed a tonic inhibition hypothesis to partially explain gustatory neocortical function. According to this view, the GN contributes to "a selective, stimulus-specific diminution of tonic inhibition of central processes that modulate food and fluid intake" and ablation of GN produces "a conspecific decrease of inhibition which results in the behavioral observation that operated rats respond associatively to novel taste stimuli as if the stimuli were familiar"' (p. 505).

If "novelty" is viewed as a function of stimulus concentration, one would predict that, in rats lacking GN, clear associative deficiencies should be obvious for higher concentrations of basic taste stimuli. That is, if the ability to appreciate the difference between experienced and novel tastes is absent in these rats, it might be predicted that an associative deficiency would become more, not less, obvious as CS concentration was increased. However, Lorden (1976) found that the relative deficiency became more obvious as a function of decreased CS concentration. This suggests that a second factor, in addition to novelty, is operating in the determination of associative taste salience. Nowlis (1974) demonstrated a "stimulus intensity dynamism" effect (Hull, 1949), which influenced both instatement and performance of a taste aversion learning habit in normal rats. Such a factor may normally add to the novelty factor in producing associative salience in taste-naive rats. If associative salience is viewed as normally an additive function of a novelty factor and a dynamism factor, as speculatively portrayed in Figure 12, then loss of the ability to respond differentially to tastes on the basis of novelty in rats lacking GN would increase the taste concentration necessary to reach an associative threshold for the taste. This would occur also in normal rats by reduction of the novelty component through familiarization with taste stimuli prior to training.

This "two-factor" hypothesis of associative salience assumes that the dynamism factor is not disrupted by the GN ablations. This assumption is based on the results of Phillips' (1977) thesis, which examined, in extinction, stimulus generalization to a series of $\mathrm{NaCl}$ concentrations in rats that had been trained extensively to avoid $120 \mathrm{mM} \mathrm{LiCl}$. As explained above, rats do not distinguish readily between equimolar $\mathrm{NaCl}$ and $\mathrm{LiCl}$ stimuli. Phillips avoided the possible problem of the differential effect of taste familiarity on training in normal and GN-lesioned rats (Kiefer \& Braun, 1977) by familiarizing the rats, before training, with the $\mathrm{NaCl}$ concentrations to be used in the generalization tests. Figure 13 displays the familiarization results in panel $\mathrm{A}$

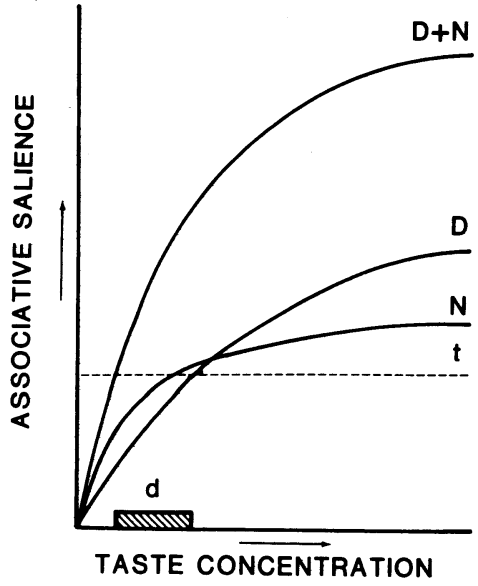

Figure 12. Hypothetical curves portraying possible influence of taste novelty $(N)$ and stimulus intensity dynamism (D), independently, on the associative salience of a particular taste quality as a function of taste concentration. In terms of the potential associative impact of a specific taste quality on the behavior of a rat, these two functions are assumed to be additive $(D+N)$ because, while a "novelty" factor may be eliminated by extensive familiarization with a taste quality, or by GN ablation, a dynamism factor would appear to persist under these conditions. The point at which line $t$ intersects the associative salience functions represents a potential concentration threshold for the effectiveness of a taste quality. The $t$ value presumably would vary as a function of experimental parameters such as US intensity, number of training trials, and variations of the CS-US time (delay) interval. The "d" on the abscissa represents the change in threshold concentration value of associative salience, for a standard set of parameters, that might occur when the novelty factor is eliminated either by GN ablation or by familiarizing normal rats with the to-beconditional taste quality prior to conditioning. In such cases, associative salience would be determined by the dynamism factor operating alone. These speculative relationships, presented graphically here for illustrative and possible heuristic value, borrowed conceptually, though not in detail, from models of the classical conditioning process (e.g., Rescorla \& Wagner, 1972).

and the generalization results, after training, in panel B. Rats lacking GN were hyperresponsive during familiarization to the two higher concentrations of $\mathrm{NaCl}$, as expected from previous work (see Figure 4); they also displayed an obvious diminution of intake as a function of increasing stimulus intensity in the generalization tests to $\mathrm{NaCl}$ following training with $120 \mathrm{mM} \mathrm{LiCl}$. It may be concluded, therefore, that rats lacking GN respond to changes in stimulus intensity during generalization tests in a manner that implies the operation of a stimulus-intensity dynamism factor.

In panel $B$ of Figure 13, it can be noted that rats lacking $\mathrm{GN}$ responded to the high test concentration of $\mathrm{NaCl}(360 \mathrm{mM})$ as though it represented a more highly concentrated example of the toxic $120 \mathrm{mM}$ $\mathrm{LiCl}$. However, they responded to the low, but detectable, $40 \mathrm{mM}$ concentration as though it was not noticeably similar to the training taste: they appeared to neglect it, showing no evidence of a generalization decrement. Normal rats, on the other hand, dis- 


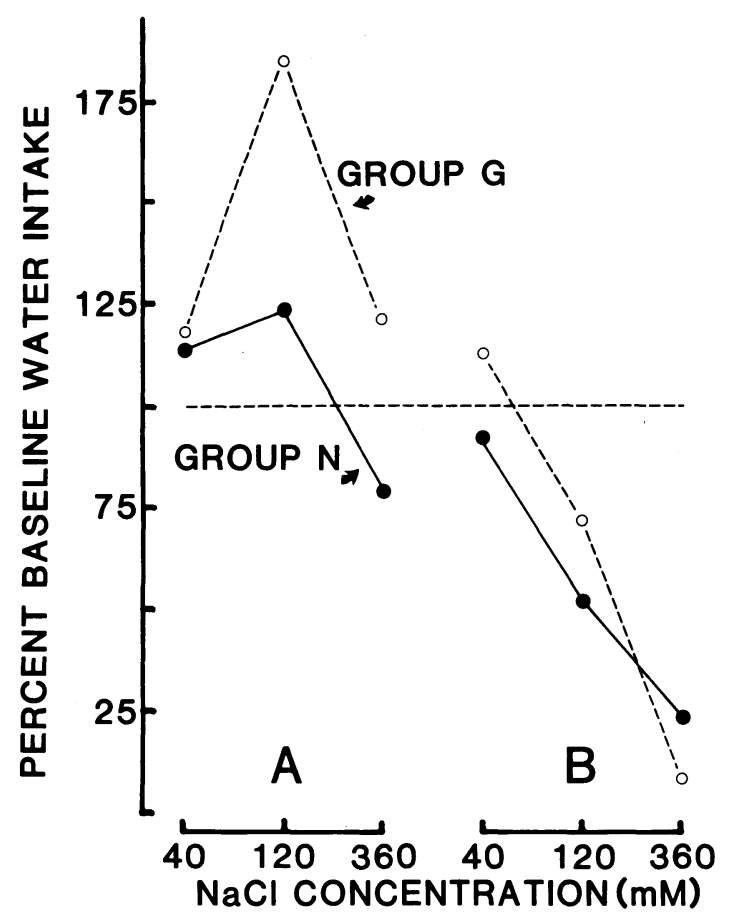

Figure 13. Panel A: Amounts consumed (percent of baseline water intake) of each of three concentrations of $\mathrm{NaCl}$ by normal (Group $\mathbf{N}$ ) and $\mathbf{G N}$-ablated (Group $\mathbf{G}$ ) rats during familiarization prior to conditioning. Panel B: Amounts consumed of the same $\mathrm{NaCl}$ concentrations by the same rats in extinction after extensive conditioning to avoid a $120-\mathrm{mM} \mathrm{LiCl}$ solution (generalization test). (Redrawn from Phillips, 1977).

played significant decrements in their responses to the $40 \mathrm{mM}$ salt concentration relative to the familiarization result. This difference, between normal and GN-ablated rats is strikingly apparent in Figure 14, which shows the results of a "threshold generalization test" conducted on the same groups of rats after extensive training to avoid $120 \mathrm{mM} \mathrm{LiCl}$. The generalization-test concentrations of $\mathrm{NaCl}$ used here were quite low, but normal rats nonetheless showed decreased intake with increasing concentration, the apparent tail of a generalization gradient presumably extending down from a peak at $120 \mathrm{mM} \mathrm{NaCl}$. Rats lacking GN, however, failed to show generalization to these low concentrations of salt. In fact, they drank significantly more of the 12 and $36 \mathrm{mM} \mathrm{NaCl}$ concentrations than they did water, an observation which simultaneously indicates (1) that these $\mathrm{NaCl}$ concentrations were detectable, and (2) that they were below a salience threshold for generalized association with $\mathrm{LiCl}$-induced toxicosis.

The generalization data reported above supports the hypothesis that GN ablation increases associative thresholds for taste stimuli independent of simple reactive thresholds, and the Kiefer and Braun (1977) experiment indicates that one important factor in this change is the reduction or elimination of differential responses to novel vs. familiar tastes. However, other factors remain to be evaluated in the light of this hy- pothesis. It is possible that postoperative acquisition becomes based on relatively subtle nongustatory cues associated with tastes. Olfactory (Benjamin, 1960) and trigeminally mediated cues are both possibilities in this regard (Kiefer, Leach, \& Braun, Note 2), as are the postingestional factors suggested by the analysis of the data for the "four taste tests" presented in the previous section of this paper. These normally less salient cues, mediated by spared neural systems, may become a foundation for the apparent associability and discriminability of operationally defined "taste" stimuli following GN ablation according to principles suggested by LeVere (1980).

\section{Summary and Conclusions}

The analysis presented above suggests that GN ablation most effectively degrades the most subtle taste discriminations, and it is hypothesized that this is due to reduced associative salience of taste stimuli. Rats lacking GN required more intense taste stimuli, greater temporal contiguity between CS and US presentations, greater stimulus dissimilarity, and/or a greater number of training trials to approach or match the efficiencies of normal rats in the acquisition of discriminatively specific learned taste aversions. While GN ablation most effectively interferes with the acquisition of the most subtle taste discriminations (Lorden, 1976; Phillips, 1977), it does not appear to interfere with basic taste reactivity (Braun \& Kiefer, 1975) which may be integrated principally at the brainstem level (Grill \& Norgren, 1978b). In addition, GN ablation interferes with the novelty-familiarity dimensions of tastes (Kiefer \& Braun, 1977), possibly through disruption of memorial taste processes (Kiefer et al., Note 2), with the result that rats lacking GN tend to respond to both familiar and novel tastes as normal rats respond to familiar tastes.

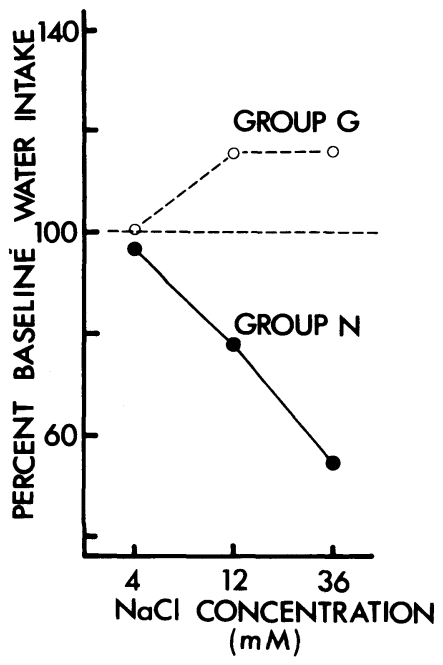

Figure 14. "Threshold" generalization test for three low concentrations of $\mathrm{NaCl}$ in normal rats (Group $\mathrm{N}$ ) and rats lacking $\mathrm{GN}$ (Group G) following extensive training to avoid $120 \mathrm{mM} \mathrm{LiCl}$. (Redrawn from Phillips, 1977). 
The apparent lack of differential responsivity to, or initial "neglect" of, novel taste stimuli probably contributes in some degree to the reduced associative salience of novel tastes. However, two observations indicate that this does not entirely account for the degradation of associative salience in rats lacking GN. First, while the novelty of a taste stimulus relative to "safe-familiar" water can be said to be a direct function of increasing taste concentration (Kalat, 1974), diminished associative salience would appear to be an inverse function of taste concentration (Lorden, 1976). In addition, a disruption of discriminative salience in $\mathrm{GN}$-ablated rats is apparent for closely similar stimuli even after extensive familiarization with various concentrations of the stimuli (Phillips, 1977).

The generality of the idea that associative salience may be disrupted, leaving fundamental detectability intact, following sensory neocortex ablation is supported by the observations of Eichenbaum, Shedlack, and Eckmann (1980) in their behavioral study of the olfactory cortex. This important work provided the first clear functional evidence of the existence of a neocortical area that could be labeled "olfactory" in rats. The area had been implicated in possible olfactory function by the anatomical work of Leonard (1969, 1972) and Krettek and Price (1977b), which showed that the orbital frontal cortex adjacent to the rhinal sulcus, immediately anterior to the GN, received projections from the mediodorsal thalamic nucleus. Eichenbaum et al. (1980) reported the selective ablation of this area of the neocortex did not impair olfactory thresholds and detectability but markedly impaired learned odor discrimination ability. Furthermore, "the learned deficit [was found to be] most apparent when the associative difficulty of the task [was] maximized by various parameters including stimulus similarity, novelty, or reversal of association"' (Eichenbaum et al., 1980). They concluded that the orbital-frontal area mediated cognitive aspects of odor-guided behavior, leaving basic sensory aspects essentially intact.

The results of studies of visual neocortex ablation in rats can be similarly interpreted. Although the analogy is strained somewhat by the quite different training and testing procedures required for the study of visual as opposed to gustatory learning processes, the comparisons nonetheless suggest some conceptual commonality of function between the visual and gustatory neocortex. Rats lacking the visual neocortex (VN) tend not to be as initially wary of the lighter side of a dark-light open field as normal rats (e.g., Altman, 1962). Thus, as rats lacking GN are not initially suspicious of novel taste stimuli, rats lacking VN display diminished suspiciousness of brightness. This analogy holds, of course, only to the degree that what can be called "photophobia" can be construed as a form of "neophobia." Much more compelling for the generality of the associative salience hypothe- sis are the following observations. Rats lacking VN readily learn brightness discrimination habits (Lashley, 1935), but with reduced efficiency (Horel et al., 1966), which can be modulated somewhat by varying the brightness intensity differences between the discriminative stimuli (Spear \& Braun, 1969). This suggests reduced associative salience of brightness stimuli for rats lacking VN, although detection thresholds for a brightness cue ultimately appear to be the same in normal and VN-ablated rats (Cooper et al., 1967; LeVere \& Mills, 1977).

Finally, we note that ablation of GN results in a loss of preoperatively instated taste habits (Braun, Kiefer, \& Ouellet, 1981; Braun, Leach, \& Kiefer, 1978; Yamamoto et al., 1980; Kiefer et al., Note 2), just as ablation of the visual neocortex results in an apparent loss of preoperatively instated visual habits in rats (e.g., Lashley, 1935; Meyer \& Meyer, 1977). This observation is the subject of the following summary and discussion of the third category of behavioral changes that we have observed following GN ablation.

\section{TASTE AGNOSIA}

In 1975 , we reported that rats failed to retain a learned taste aversion to $150 \mathrm{mM}$ sucrose after GN ablation (Ouellet, Kower, \& Braun, Note 3.). In this pilot study, it first had been determined that normal rats could retain such an aversion for a period of 1 month, which was the intended duration of the postoperative recovery period. The same rats then were subjected to additional training, following which half of them received GN ablations. After the recovery period, it was found that the GN-ablated rats responded to the sucrose solution as though they had not been trained, whereas unoperated control rats displayed perfect retention. Thus, despite two preoperative training regimens, separated by 1 month, the preoperatively instated habit appeared to be lost following GN ablation. This finding was reminiscent of Lashley's results with a brightness discrimination habit when he found that, despite more than 1,000 trials of overtraining, visual neocortex ablation resulted in complete agnosia for the visual habit (Lashley, 1921).

We later reported more comprehensive observations concerning the taste agnosia effect (Braun, Leach, \& Kiefer, 1978) and finally published a complete account (Braun, Kiefer, \& Ouellet, 1981). The latter study appeared after a report of the same effect by Yamamoto et al. (1980), in which the taste aversion habits had been preoperatively instated using a one-trial training procedure pairing $100 \mathrm{mM}$ $\mathrm{NaCl}$ with $\mathrm{LiCl}$ injections: Postoperative agnosia for the $\mathrm{NaCl}$ conditional stimulus was evident for rats with GN lesions.

The study by Braun et al. (1981) used $150 \mathrm{mM}$ sucrose and $150 \mathrm{mM} \mathrm{NaCl}$ as conditional stimuli and employed a repeated-trials training procedure with 


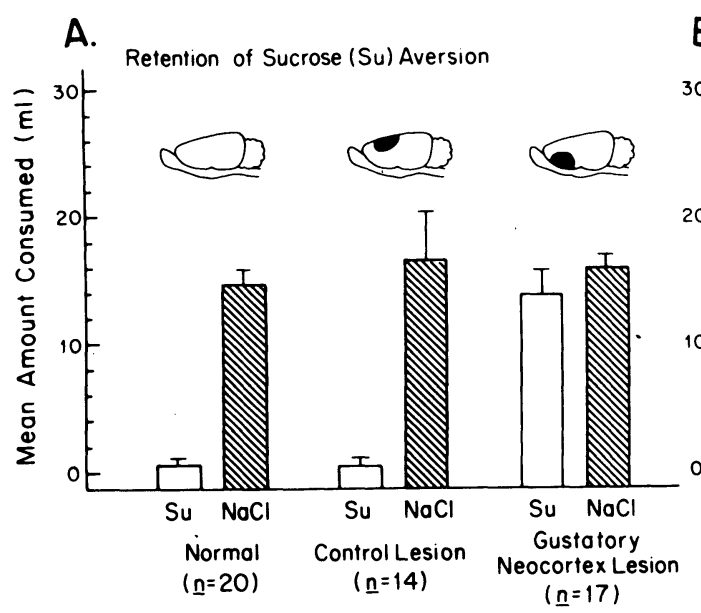

C.

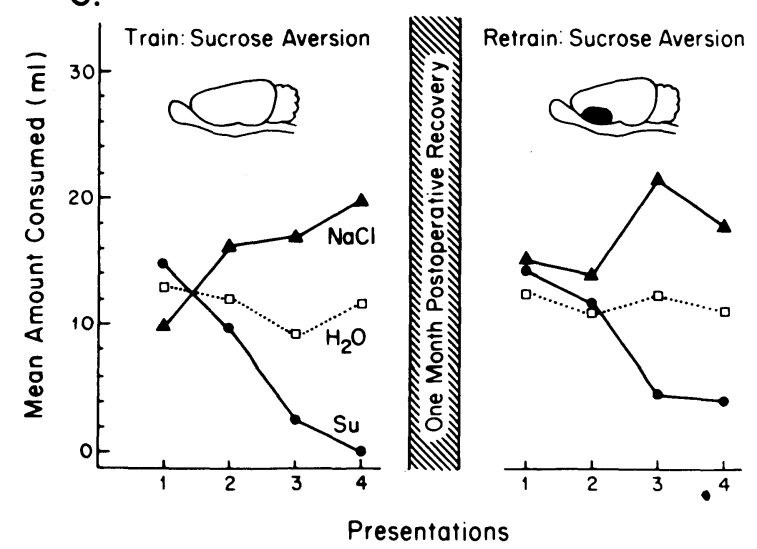

B.

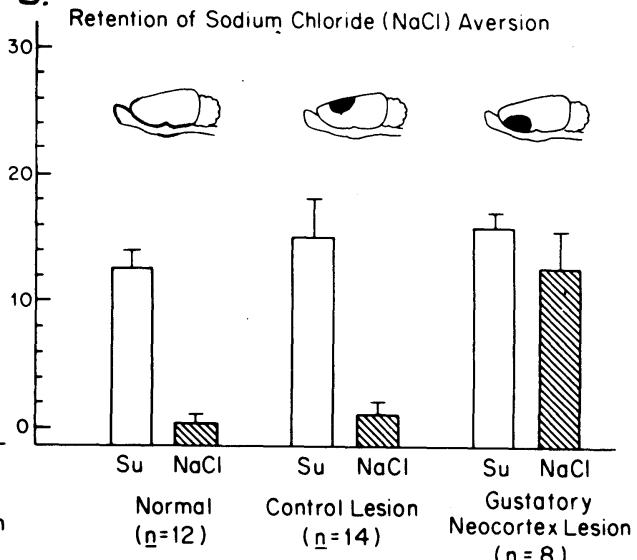

D. Gustatory Neocortex Lesion
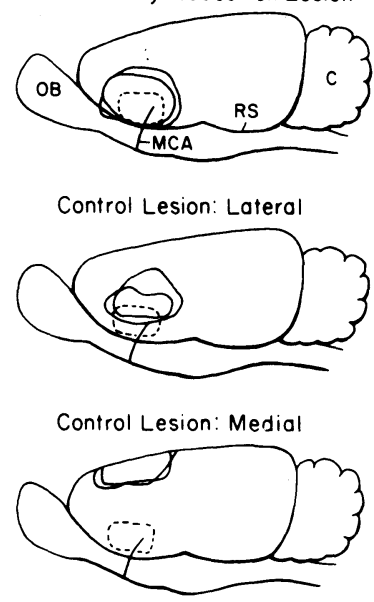

Figure 15. Effects of GN ablations on the retention of preoperatively learned aversions to either sucrose (A) or $\mathrm{NaCl}$ (B): the mean and SEM are portrayed for each group. Normal and control lesion rats displayed complete retention of the aversions, while GN ablation resulted in complete loss of the aversions. However, as shown in panel C, rats lacking GN relearned a discriminatively specific aversion to the sucrose stimulus. Panel D shows lateral views of the rat's brain depicting the area of the GN (dotted line) relative to the areas encompassed by the three kinds of cortical lesions (solid lines) employed in this study. Lesions of the right and left hemispheres are portrayed on one side to illustrate their relative symmetry. The two control lesion subgroups behaved as normal rats in these tests and were combined into one "control lesion" group for presentation in panels $A$ and B. Abbreviations: $C=$ cerebellum, $M C A=$ middle cerebral artery, $O B=$ olfactory bulb, RS $=$ rhinal sulcus. (From Brown et al., 1981).

$20-\mathrm{mg} / \mathrm{kg}$ ip injections of apomorphine hydrochloride serving as the US. Complete agnosia was found for both of the taste stimuli following GN ablation, whereas normal rats clearly retained discriminatively specific aversions to each of the stimuli (Figure 15). It was found also that the taste agnosia was specific to ablation of GN because control lesions of somatosensory cortex adjacent to $\mathrm{GN}$, often overlapping the dorsal portion of the classically defined gustatory area (Benjamin \& Pfaffmann, 1955), had no observable effect on the postoperative retention of the taste habits. Furthermore, it was shown that discriminatively specific taste aversion habits could be relearned, as expected from the prior observations of original learning in rats lacking GN (e.g., Kiefer \& Braun, 1977, 1979), but there was no indication of savings as a result of the preoperative training. Therefore, while the preoperatively instated taste engram appeared to be lost, taste memory capacity per se was intact.

Subsequent studies were designed to test whether the agnosia was specific to taste stimuli and whether it was a general effect across the four basic taste qualities (Kiefer et al., Note 2). Since only taste retention had been evaluated up to this point, it remained possible that the effect was a general one for habits established using the taste aversion learning paradigm-that the retention deficit might be based on agnosia for the visceral US. Cortical representation of visceral afferents ventral to gustatory areas was clearly implied by Woolsey's somatic sensory maps of the neocortex, which consistently displayed the tongue protruding backward from the mouth; this intimated representation of the visceral surfaces of the body, ventrally on the cortex, as the gastrointestinal tract would 
be descended from the back of the tongue (Woolsey, 1958). Furthermore, Hankins et al. (1974) reported evidence of disrupted "buzzer-shock" conditioning following small anterolateral cortical lesions, and this suggested the possibility that behavioral disruptions produced by anterolateral lesions might have little to do with taste per se. Kiefer et al. (Note 2) found that rats lacking $\mathrm{GN}$ retained a preoperatively learned odor aversion to benzyl acetate but lost a learned taste aversion to $290 \mathrm{mM}$ sucrose. We viewed this as especially convincing evidence of the taste specificity of the agnosic effect following GN ablation because both taste and odor habits had been preoperatively instated in the same rats using the same training procedure, and the odor and taste stimuli had been compounded during one phase of the preoperative training regimen. The dissociation between taste and odor following GN ablation has been recently confirmed by Kiefer, Rusiniak, and Garcia (in press).

Since only positively hedonic sucrose and $\mathrm{NaCl}$ CSs had been employed in the original experiments demonstrating the agnosic effect (e.g., Braun et al., 1981; Yamamoto et al., 1980), it remained possible that the effect would not be apparent for negatively hedonic acid and quinine CSs. Kiefer et al. (Note 2) tested this possibility and found that taste agnosia was apparent for preoperatively acquired aversions to quinine hydrochloride $(.1 \mathrm{mM})$ and hydrochloride acid $(10 \mathrm{mM})$ solutions following $\mathrm{GN}$ ablations. However, more extensive lesions were necessary to obliterate the acid habit. Lesions that consistently eliminated quinine and sucrose aversion were not necessarily also effective in eliminating a learned acid aversion. The GN lesion effective for acid extended more deeply into the insula, adjacent to the claustrum, and were more extensive anteriorly. We extended GN lesions dorsally into somatosensory neocortex to test the hypothesis that acid retention was maintained by tactile cues which accompany the acid $\mathrm{CS}$, but these lesions did not produce an effect greater than that of lesions relatively restricted to the GN area. Therefore, we were unable to satisfactorily determine why acid aversion retention was more resistant to agnosia than either sucrose or quinine aversion retention. Either acid has a different, perhaps more extensive, cortical representation in the taste area or retention may be maintained by olfactory or visceral cues that accompany the acid stimulus. The more extensive invasion of the "olfactory" cortex (Eichenbaum et al., 1980; Leonard, 1969, 1972) adjacent to $G N$ in the lesions that effectively eliminated acid CS retention suggests the former alternative. The obvious subjective postingestional sensory consequences of consuming small amounts of 10 to $50 \mathrm{mM}$ $\mathrm{HCl}$ by one of the present experimenters (J.J.B.) suggests the possibility of distinctive visceral cues.

Regardless of the ultimate resolution of the anomaly found when an acid stimulus is used as a CS, this difficulty should not obscure the general observation that lesions centered on the GN produce agnosia for basic tastes, and that the agnosia is specific both to taste stimuli and to the anterolateral placement of the cortical lesions. Gustatory neocortex appears to be normally involved in the memorial representations of the adaptive significance of taste stimuli. The additional observation of reduced or eliminated neophobia for tastes in rats lacking GN (Kiefer \& Braun, 1977) supports this generalization by indicating that the operated rats no longer discriminate familiar from novel tastes: The recognition of what is "new" obviously must be based on the ability to recognize what already has been experienced.

Kiefer et al. (Note 2) offered the suggestion that agnosia for the learned significance of taste stimuli following GN ablation might be restricted to learned behaviors that are specifically cued by a taste. We based this suggestion partially on the observation that rats do not appear to lose the learned ability to find $\mathrm{NaCl}$ solutions in response to sodium depletion when the GN is ablated (Wirsig \& Grill, in press); this learned response presumably is triggered by the physiological consequences of sodium deprivation rather than by the taste of $\mathrm{NaCl}$ (Krieckhaus, 1970; Wolf, 1969). Likewise, the potentiated salience of odorconditional stimuli when they are presented in conjunction with a taste cue (e.g., Braun \& Ryugo, 1974; Garcia \& Rusiniak, 1980) is not greatly degraded by GN ablation, but these lesions clearly degrade the associative salience of the taste cue itself (Kiefer et al., in press). The memorial and acquisition disruptions observed following GN ablation therefore may be highly specific to learned behaviors that are directly prompted by conditional taste stimuli. Whether this is true also in other kinds of taste learning paradigms, or is specific to taste aversion learning, remains to be determined.

\section{A Hierarchical View}

The generality of the finding of specific sensory agnosia following ablation of relevant sensory neocortex has been mentioned elsewhere (Braun et al., 1981; Kiefer et al., Note 2), and the paradox posed by this effect has been most thoroughly discussed with regard to the visual neocortex of the rat by Meyer and Meyer (1977). While it is tempting (and easiest) to interpret the agnosia as representing a distinct loss of a preoperatively instated engram, to do so would be a step backward (see LeVere, 1980, Meyer, 1972, and Meyer \& Beattie, 1977, for thoughtful discussions of this general problem). Taste agnosia is, however, a crisp and distinct effect following GN ablation, and its ubiquity suggests a key to a conceptual understanding of the gustatory system from a hierarchical perspective (Jackson, 1890/1958; Pavlov,1927/1960).

In the Jacksonian view, the loss of objective evidence of the normal associative link between a taste 
CS and its consequence (the US) probably would be interpreted as a dominant "symptom" of GN ablation; the task would be to understand the basis of this symptom, which, as we have shown, is neither an inability to respond differentially to tastes nor an inability to appreciate or utilize the US. However, as reviewed in a previous section of this paper, learning following GN ablation is degraded relative to normal in a direction that implies reduced associative salience for taste stimuli: Low concentrations of taste solutions often are not readily conditionable (Braun et al., 1972; Lorden, 1976), the discriminative grain is less precise (Kiefer \& Braun, 1979; Lorden, 1976), there is less tolerance for long CS-US delays (Lorden, 1976), generalization decrement effects to low (albeit detectable) concentrations of a taste stimulus may not be evident (Phillips, 1977), and neophobic tendencies are greatly reduced or eliminated (Kiefer \& Braun, 1977).

Viewed individually, the changes, or "symptoms," listed above may seem "minor" (e.g., Scott \& Perrotto, 1980); taken collectively in the context of their implications for the adaptive flexibility of tasteguided behavior in the rat, however, these effects of GN ablation are far from trivial. They are all in the direction of reduced precision and efficiency of taste learning, and from a hierarchical point of view, they imply a greatly changed central representation, or rerepresentation (Jackson, 1890/1958), or specifically associative neural patterns for taste stimuli. Thus one may speculate that the afferent representation of a specific taste has become, for the rat, a markedly altered conditional stimulus, and that a change in the neural pattern of representation is the foundation of agnosic taste effects following GN and/or other (amygdala, Nachman \& Ashe, 1974) forebrain lesions (see the concluding remarks for elaborations of this point of view from a neurophysiological perspective).

Presumably, as the neuraxis is descended and portions of "higher level" components of the central gustatory system are progressively eliminated, tasterelated behavior should become more stereotyped and less flexible. In this regard, it is instructive to compare the kinds of behavioral changes that follow GN ablation with the kinds of changes observed following decerebration. Grill and Norgren (1978a, $1978 b, 1978 \mathrm{c}$ ) found that while reflexive hedonic responses (mimetic responses) to taste stimuli appeared essentially normal in decerebrated rats, such preparations failed to learn an aversion to sucrose after as many as 12 pairings of a sucrose $\mathrm{CS}$ with $\mathrm{LiCl}$ injections. Thus, while reactive salience to taste stimuli was preserved in decerebrated rats, associative salience appears to have been eliminated.

In conclusion, with regard to the Jacksonian perspective (Jackson, 1890/1958), the studies reviewed here move toward making more explicit the kinds of capacities that are diminished when at least one supraordinate level of the hierarchy, the GN, is eliminated from the taste system. This begins to address a valid and friendly criticism of such theorizing that was offered by Grill and Norgren (1978b), whose own work has contributed greatly to the revitalization of a hierarchical point of view.

\section{FILLING IN THE GAPS: A VIEW FROM THE TOP}

We have emphasized what we believe to be a productive kind of analysis of brain-lesion effects. It is essentially an empirical "syndrome" analysis, in the spirit of views offered by Jackson $(1890 / 1958)$ and Luria (1966). Traditionally, with regard to any specific area of the neocortex, if one asks whether it is necessary for a particular behavioral capacity, the answer seems always to be "no" (e.g., Lashley, 1950). This was the fundamental observation that led Jackson to emphasize the "vertical" arrangement of the nervous system and was the focus of contention leading away from the classical functional localization perspective (see Luria, 1966). On the other hand, if one asks whether a specific neocortical area is involved in a particular behavioral capacity, the answer seems invariably to be "yes." This is true even for behaviors that appear to be fundamental "brainstem" reflexes. For example, the results of K. U. Smith's studies of eye movement suggested that optokinetic nystagmus responses in cats were not affected by visual cortex ablations (e.g., K. U. Smith, 1937): Later work revealed, however, that under monocular viewing conditions nystagmus responses were severely degraded relative to normal when a visual field was rotated in a nasal-to-temporal direction with respect to the viewing eye (Wood, Spear, \& Braun, 1973; see, also, Braun, 1978). Thus, specific experimental conditions were found by which clear involvement of the visual cortex in this simple behavior became evident. Likewise, fundamental reactivity to taste stimuli is affected by GN ablation, but in a manner suggesting altered, rather than diminished, taste reactivity. Overall, we have failed to identify a category of taste-guided behavior that is unaffected by GN ablation.

To be sure, in the early 1970 s it seemed possible that the taste system might differ from every other sensory system with regard to involvement of the neocortex in sensory-specific cognitive processes. The cortical spreading depression (CSD) literature contributed to this view when it was demonstrated that rats trained to avoid a taste cue under unilateral CSD showed clear transfer of the learning to the depressed hemisphere (Best \& Zuckerman, 1971). It was concluded from this observation that the taste aversion learning engram, or trace, was principally a subcortical phenomenon. However, Burešova and Bureš (1973) paired .1\% saccharin with $\mathrm{LiCl}$ injections and reported that taste aversion learning was not evident 
if both CS and US were presented while the rats were under bilateral CSD. On the other hand, if the taste CS was presented 15 min prior to CSD and the LiCl US was injected during spreading depression, taste aversion learning was essentially unimpaired relative to control groups. However, they noted that, as the CS-US delay was increased, "the gustatory trace decayed under bilateral CSD more extensively than in normal animals" (p. 695). As we have noted, this conforms to our results with rats lacking GN: a .1\% saccharin cue was not readily conditionable (Braun et al., 1972), and taste performances were degraded more rapidly than normal under CS-US delay conditions (Lorden, 1976).

Burešova and Bureš (1973) suggested that Best and Zuckerman's (1971) rats were not completely depressed during the eight training trials that had been used to instate the learned aversion to saccharin. This suggestion was reinforced by behavioral and electrophysiological observations of increased difficulty in producing effective CSD as a function of repeated treatments (Nadal, 1971; Petrinovich, 1976). The suggestion that Best and Zuckerman's (1971) conclusions were in error was also reinforced by the results of a thoughtfully designed CSD study by Lehr and Nachman (1973), who, using a one-tool training procedure, found clear lateralization of a learned $\mathrm{LiCl}$ aversion and concluded that "single trial learned taste aversions are normally cortically mediated" (p. 82). This interpretation was then obfuscated by the demonstration that CSD can itself serve as a US in taste aversion learning (Winn, Kent, \& Libkuman, 1975). Furthermore, Winn et al. interpreted their data to support the conclusion that taste aversion learning might be subcortically mediated.

There are undoubtedly several reasons for the contrasting conclusions provided by the CSD literature concerning subcortical vs. cortical mediation of taste aversion learning, reasons that may be related to fundamental differences in design and implementation of the various studies, but resolution of the controversy can be suggested from the work reviewed here. Everybody was right. The neocortex is clearly involved, but not essential, in the establishment and retention of a taste aversion learning engram.

The symptoms of GN lesions summarized in this review are not conspicuously apparent: The GN does not appear to be the sine qua non of any particular class of psychological taste processes. Taste reactivity, learning, and memory functions are present in rats lacking GN. In view of this, the question to answer becomes: How is the gustatory neocortex involved? This question invokes the continuing problem of brain lesion studies: How does one understand the function of a part of a system by analyzing the functions expressed by the interactions of the parts remaining after ablation? As discussed in an earlier paper (Braun, 1978), inferences of function based on brain lesion studies necessarily require a thor- ough analysis of a range of manifest symptoms of the brain damage, and an analytical comparison of the profile of these symptoms with the profiles of symptoms provoked by damage to other parts of the system. The work reviewed here provides a step in this direction.

The kinds of influences on taste-guided behavior that may be inferred for the GN most obviously seem to be in the "cognitive-discriminative" (Pfaffmann et al., 1977) realm: Taste stimuli to which rats lacking the entire forebrain can differentially react (Grill $\&$ Norgren, 1978b) are greatly reduced in their effectiveness as associative cues in learning and memory tasks in rats lacking GN. In other words, an apparent dissociation between what we have called "reactive salience" and "associative salience" seems evident from the studies summarized above. However, it is important to stress that we do not view this as a dissociation of "kind," but a dissociation of relative emphasis of involvement of various portions of the central gustatory system in taste-guided behavior.

A clear view of the gustatory system from any research perspective obviously necessitates convergent data from a number of approaches. With this in mind, we conclude with a brief discussion of relevant selected studies of gustatory neurophysiology and consider the results of some studies of lesions to parts of the gustatory system other than the GN.

\section{Gustatory Neurophysiology and Associative Salience}

Although most of the electrophysiological data on gustatory responses have been collected from the primary afferent taste nerves and from within the brainstem, these data are nonetheless highly relevant to a theoretical understanding of GN processes. The most interesting work in this regard stems from the original analyses of across-fiber firing patterns relative to the neural coding of taste (Erickson, 1963) and the accompanying theoretical perspective (patterning theory) that developed from Pfaffmann's original observations (Pfaffmann, 1941). We will briefly consider (and take liberties with) the theory as it might apply to a conception of GN function in taste encoding.

The following comments focus on the inference that GN ablation degrades the associative salience of taste stimuli. It may be proposed that diminished associative salience corresponds to degradation of normal patterns of neural activity following GN ablation. If one assumes that taste-elicited neural activity ascending through successive synaptic junctions in the taste pathway reflects increasing amplification, resolution, and/or redundancy that is initiated by an adequate sapid stimulus (J. R. Ganchrow \& Erickson, 1970; Scott \& Erickson, 1971), then degradation of the activity should be associated with concomitant decreases in the behavioral impact and resolution of that stimulus.

However, there is the problem of accounting from 
this perspective for the relative lack of effect of GN lesions on preference/detection response functions for intensities of taste stimuli close to the reactive thresholds. These functions should also be degraded by GN lesions. Because they are not, and because of the clear influences of $\mathrm{GN}$ lesions on the associative utility of taste cues, our heuristic assumption has been that there is a dissociation between reflexive and associative subsystems within the gustatory system. The integrative emphasis of the reflexive system appears to be primarily at the level of the lower brainstem, whereas the associative functions are believed to be increasingly represented as the gustatory system is ascended (see the hierarchical perspective presented under “Taste Agnosia").

This idea of hierarchical separation of reactive from associative functions in the taste system is not new in principle (e.g., Nowlis, 1977; Pfaffmann et al., 1977), and it is supported by many published observations described throughout this paper. An anatomical/electrophysiological corollary of this dissociation may be reflected also in the results of a recent neurophysiological study: Scott and Perrotto (1980) contrasted the correlation between neural responses in the pons and medullary taste areas (.98) to sapid stimulation of the tongue, over a wide range of concentrations of four taste stimuli, with the correlation obtained between the pons and the gustatory thalamus (.55) to the same stimuli. They concluded that "a major dichotomy exists between brain stem and forebrain coding for taste" (p. 739) and suggested that the dichotomy might reflect a thalamic confluence of ascending and descending processes relevant to the modulation of brainstem taste reflexes. To the degree that the modulatory processes include asociative taste processes, the dichotomy can be said to reflect dissociation between these processes and basic taste reactivity.

The following observations suggest a more direct congruence between behavioral and electrophysiological measures with regard to interpreting GN ablation effects. With respect to taste discriminability ("discriminative salience"), the high degree of behavioral generalization between $\mathrm{LiCl}$ and $\mathrm{NaCl}$ (e.g., Nachman, 1963) corresponds to the high degree of similarity of neural responses in the chorda tympani (Beidler, 1953), solitary nucleus (Doetsch \& Erickson, 1970), and the pons (Perrotto \& Scott, 1976) in response to the application of these two salts to the tongue. The discriminability of these two stimuli by normal rats may depend on the amplification or other elaboration by forebrain systems of subtle differences between the stimuli. Rats lacking GN failed to discriminate equimolar $\mathrm{LiCl}$ and $\mathrm{NaCl}$ stimuli on the basis of taste when the stimuli were presented at clearly suprathreshold detection levels. They also did not generalize a learned $\mathrm{LiCl}$ aversion to concentrations of $\mathrm{NaCl}$ near the reactive threshold, and in fact displayed evidence of actually preferring these stimuli to water (see Figures 10 and 14 plus accompanying discussion; Phillips, 1977). These behavioral observations correspond well with the suggestion generated (admittedly post hoc) by the electrophysiological observations.

As stated by Scott (1974), "A basic tenet of the [patterning] theory is that the degree to which two taste stimuli are behaviorally discriminable is inversely proportional to the correlation coefficient between their neural patterns"' (p. 413). Scott selected taste stimulus pairs graded on the basis of similarity (from "similar" to "very distinct"), as determined from neural discharge rates to each of the stimuli at the levels of the solitary nucleus (NTS) and gustatory thalamus. He then associated one stimulus of each pair with x-radiation treatment (a malaise-inducing US) in different groups of rats. In subsequent tests, he measured the duration of licking that was required for the rats to discriminate between the two taste stimuli. Close correspondence was found between the licking measure and the neural measures of correlation between the taste pairs: Longer licking times were required to discriminate two tastes that had a relatively high correlation between their neural patterns. We would predict that the behavioral-electrophysiological (NTS) correspondence should be even closer when the gustatory neocortex is removed; this should occur in proportion to the degree that resolution of a specific taste signal is degraded in the operated rats. Residual discriminative capacities of rats lacking GN, as measured in learning tasks, may become based more directly on lower order patterns of taste representation.

\section{Gustatory Thalamus and Amygdala}

The GN appears to be a principle terminus for three major forebrain taste pathways from the pontine taste area: a ventral pathway via the amygdala, a dorsal pathway via the gustatory thalamus (see Norgren \& Pfaffmann, 1975, and Pfaffmann et al., 1979), and a direct projection via the internal capsule (Lasiter et al., 1982). Thus, the relative contributions of these three projection pathways to taste-guided behavior relate most directly to considerations of GN functioning. Here we will discuss two of thesethalamic and amygdaloid.

Thalamus. While ablation of taste thalamus results, according to consummatory measures, in almost complete elimination of taste reactivity in rats across all four taste modalities (Ables \& Benjamin, 1960; Oakley \& Pfaffmann, 1962), decerebration leaves hedonic (mimetic) responses intact (Grill \& Norgren, 1978b). The latter observation indicates that the taste thalamus cannot be regarded as a "center" for differential taste reactivity. Rather, biased modulatory processes that may be released and/or perturbed by a thalamic lesion appear to sharply attenuate the expression of intact reflexive taste sensitivity.

The reported behavioral results of gustatory thala- 
mus damage are difficult to fit into a broad scheme that systematically relates components of the taste system to influences on taste-guided behavior. Anatomical and electrophysiological observations of relationships between the gustatory thalamus and the GN, the somatosensory system (Burton \& Benjamin, 1971; Scott \& Erickson, 1971), the olfactory system (Giachetti \& MacLeod, 1977; Powell, Cowan, \& Raisman, 1965), the hypothalamus (Emmers, 1977; Norgren, 1976), and pontine taste area (see Norgren, 1977) suggest the thalamus as a focus for the expression of taste behavior symptoms following other forebrain lesions. However, the apparent neutralization of hedonic preferences and aversions to taste stimuli following thalamic lesions (Ables \& Benjamin, 1960; Oakley \& Pfaffmann, 1962), an effect that is not at all apparent following either GN ablation or decerebration, suggests the presence of a second focus in addition to the ventrobasal thalamus.

Hedonic taste responses, as operationally defined, are lost following gustatory thalamus lesions. As suggested in the introduction to this section of the paper, this implies that other descending influences are released which actively neutralize the intact behavioral hedonic response capacities of the rat. That these speculated descending influences may originate in the forebrain is implied by Grill and Norgren's (1978b) findings with "thalamic" preparations (forebrain removed): In these rats, removal of the telencephalon appeared to release a general reflexive aversion response to all taste stimuli, like that seen for quinine both in normal and in decerebrated rats (Grill \& Norgren, 1978a, 1978b). Congruent with this, stereotyped aversion responses dominate when the gustatory thalamus is stimulated (Norgren, 1970b). Thus, when the thalamus is intact, but bereft of telencephalic influences, generalized taste rejection is observed. On the other hand, elimination of the gustatory thalamus, leaving the rest of the forebrain intact, results in neutralization of hedonic responses to taste stimuli (rats with thalamic lesions respond to the different tastes as they respond to water).

The observations cited above imply that normal modulation of a reflexive preference and aversion functions, which are fully realized at the brainstem level, is based on an interaction between at least two different sets of descending forebrain influences on brainstem taste-response areas: One originates in the thalamus, and the other remains to be specified. This suggestion is somewhat speculative, however, because different procedures were used to measure the phenomena summarized above. Grill and Norgren (1978b) based their conclusions with thalamic and decerebrate preparations on measurements of mimetic responses to tastes, and the other studies employed consumatory measures. A fundamental dissociation of these two kinds of responses is clearly possible.

The excellent summary and discussion of thalamic processes by Scott and Perrotto $(1980$, p. 748$)$ indicates the possibility that taste rejection processes via the thalamus represent the tonic basis upon which experientially based modulatory processes are orchestrated in consumatory behavior. Bitter (quinine) is the only taste quality that produces thalamic responses that correlate highly $(+.96)$ with brainstem responses, according to Scott and Perrotto's electrophysiological criteria. Corresponding to this, the acquisition of learned taste aversions to quinine may be least perturbed by $\mathrm{GN}$ ablations as compared with sucrose, $\mathrm{NaCl}$, and $\mathrm{HCl}$ acquisition (Lorden, 1976). Thus, the gustatory thalamus seems to be a likely focus for stimulus-specific modulation of learned taste aversions. The degree to which this may also be true for the modulation of learned taste preferences (e.g., Garcia, Ervin, Yorke, \& Koelling, 1967; Rozin $\&$ Kalat, 1971) remains to be determined.

Loullis, Wayner, and Jolicoeur (1978) reported that some capacity to acquire a taste aversion habit appeared to be present in rats with gustatory thalamus lesions, although severe attenuation of learning was found. However, the experiment did not include controls for sensitization effects or for assessing the discriminative specificity of the taste aversion. In addition, the reconstruction of one representative thalamic lesion that was presented (Figure 1, Loullis et al., 1978) suggests, in our judgment, that ventral, posterior portions of the gustatory thalamus may have been spared in some of the preparations upon which the behavioral analysis was based. It is therefore difficult to interpret these findings. In an earlier study by Oakley (1965), an operant conditioning paradigm was employed in an attempt to assess the reinforcing properties of taste stimuli in rats with gustatory thalamic lesions. The generalized effects of the lesions on performance capabilities, as compared with those of normal control rats, severely limited the conclusions that could be drawn from the results of Oakley's (1965) study. This suggests a special importance of having adequate controls, for generalized performance deficiencies, in studies of the effects of thalamic lesions on associative taste processes.

Amygdala. Kiefer and Braun (1979) noted that most of the major symptoms of GN ablation have also been described following lesions of the basolateral amygdala (See Aggleton, Petrides, \& Iversen, 1981; Nachman \& Ashe, 1974). These effects include taste agnosia, diminished neophobia, disrupted taste aversion acquisition (Nachman \& Ashe, 1974), and hyperresponsiveness to suprathreshold sucrose solutions (Rolls \& Rolls, 1973). Nachman and Ashe (1974) interpreted their findings as suggesting that rats with amygdala lesions "have deficits in recognizing the significance of stimuli"' (p. 622). Their operated rats had failed to respond differentially to the novelty of the taste stimuli and had failed to retain a preoperatively instated sucrose aversion habit, yet basic taste reactivity was clearly present. 
The essential similarity between the patterns of taste-behavior symptoms produced by GN and amygdaloid lesions suggests that the ventral pathway from the pontine taste area collectively emphasizes the capacities implied by the symptoms. However, there are also important differences between the effects of GN and amygdaloid lesions. The symptoms of GN lesions appear to be fairly specific to taste stimuli per se (Kiefer et al., Note 2), and natrorectic adjustments to sodium depletion seem to be relatively unaffected (Wirsig \& Grill, in press; Wolf et al., 1970). On the other hand, as pointed out by Nachman and Ashe, amygdaloid lesions result in a wide variety of learning deficiencies (e.g., McGowan, Hankins, \& Garcia, 1972; Pellegrino, 1968) and clear disruptions of behavioral sodium homeostasis are observed (Nachman \& Ashe, 1974).

As suggested above for amygdala lesions, while the effects of lesions to brain areas other than the GN may be clearly evident in measures of taste-guided behavior, such effects may be evident for many other kinds of behaviors as well. Rats with lateral hypothalamic lesions, for example, were found to retain a preoperatively learned taste aversion, but appeared unable to acquire a new taste aversion habit (Schwartz \& Teitelbaum, 1974). This indicates a dissociation of systems involved in taste retention from those involved in learning, just as the opposite result, apparent loss of preoperatively acquired taste habits but sparing of the capacity to learn new ones following GN lesions (e.g., Braun et al., 1981), indicates such a dissociation. However, as Schwartz and Teitelbaum (1974) point out, the effects of hypothalamic lesions appear to be generalizable to many kinds of learning. Thus, compared with lesions of other prosencephalic brain areas, a relative specificity of symptoms to the cognitive processing of taste stimuli may prove to be a distinctive feature of GN ablation.

Especially interesting to consider in interpreting the similarities of taste-related symptoms of amygdala and GN lesions are the following anatomical pathways: (1) direct pontocortical projections from the pontine taste area (PTA) to the insula, (2) direct projections from PTA to central amygdala, and (3) direct projections from lateral amygdala to insular cortex (see Figures 1 and 2 plus the associated narrative). Amygdaloid lesions would leave " 1 "' intact, and GN ablation would leave " 2 " intact, either of which might serve as a structural foundation for the residual learning or relearning capacities displayed by rats with either amygdaloid or GN lesions. It is likely that the normal interaction of these two brain areas contributes greatly to the associative salience of taste stimuli, and damage to both areas might be found to eliminate discriminative taste aversion learning altogether.

Reprise. Neocortical projections from the amygdala and ventrobasal thalamus appear to be segre- gated in the gustatory neocortical zone: The thalamic gustatory projections are principally focused surrounding the middle cerebral artery, distinctly above the rhinal sulcus; the pontocortical and amygdalocortical projections appear to be focused more on the insular area. The relatively large lesions employed in our original studies included both of these areas. Yamamoto et al. (1980) found that lesions restricted to within the rhinal bank produced agnosia for a learned taste aversion, whereas lesions confined to more dorsal areas had little effect. In addition, Lasiter and Glanzman (1982) recently found that selective insular lesions produced by electrocoagulation resulted in disruption of $\mathrm{LiCl}$ aversion learning, but similar localized lesions of the "somatic" gustatory area were essentially without effect on the acquisition of the taste habit. Thus, these initial data begin to provide indications of structural dissociation of functional contributions with subareas which we have collectively called the "gustatory neocortex."

\section{REFERENCE NOTES}

1. Lasiter, P. S., \& Glanzman, D. L. Thalamic and cortical projections of the pontine taste area: $A$ retrograde fluorescent dual-labeling study. Manuscript in preparation, 1982.

2. Kiefer, S. W., Leach, L. R., \& Braun, J. J. Taste agnosia following gustatory neocortex ablation: Dissociation from odor and generality across taste species. Manuscript submitted for publication, 1981.

3. Ouellet, J. V., Kower, H. S., \& Braun, J. J. Failure to retain a learned taste aversion after lesions of the gustatory neocortex. Paper presented at the meeting of the Western Psychological Association, Sacramento, April 1975.

\section{REFERENCES}

Ables, M. F., \& Benjamin, R. M. Thalamic relay for taste in the albino rat. Journal of Neurophysiology, 1960, 23, 376-382.

Adrian, E. D. Olfactory reactions in the brain of the hedgehog. Journal of Physiology (London), 1942, 100, 459-473.

Aggleton, J. P., Petrides, M., \& Iversen, S. D. Differential effects of amygdaloid lesions on conditioned taste aversion learning by rats. Physiology \& Behavior, 1981, 27, 397-400.

Allen, W. F. Origin and distribution of the tractus solitarius in the guinea pig. Journal of Comparative Neurology, 1923, 35, 171-204.

Altman, J. Effects of lesions in central nervous visual structures on light aversion of rats. American Journal of Physiology, 192, 202, 1208-1210.

Åström, K. E. On the central course of afferent fibers in the trigeminal, facial, glosopharyngeal, and vagal nerves and their nuclei in the mouse. Acta Physiologica Scandinavica (Suppl. 106), 1953, 29, 209-320.

Bagshaw, M. H., \& Pribram, K. H. Cortical organization in gustation (Macaca mulatta). Journal of Neurophysiology, 1953, 16, 499-508.

Barker, L. M., Best, M. R., \& Domjan, M. (Eds.). Learning mechanisms in food selection. Waco, Tex: Baylor University Press, 1977.

BARNETT, S. A. Experiments on "neophobia" in wild and laboratory rats. British Journal of Psychology, 1958, 49, 195-201.

Bartoshuk, L. M. Water taste in man. Perception \& Psychophysics, 1968, 3, 69-72.

Bartoshuk, L. The chemical senses. I. Taste. In J. W. Kling \& L. A. Riggs (Eds.), Woodworth and Schlosberg's experimental 
psychology (3rd ed.). New York: Holt, Rinehart \& Winston, 1971.

Beidler, L. M. Properties of chemoreceptors of tongue of rat. Journal of Neurophysiology, 1953, 16, 595-607.

Beidle R, L. M. A theory of taste stimulation. Journal of General Physiology, 1954, 38, 133-139.

Beidle R, L. M. Taste receptor stimulation. In J. A. V. Butler, H. E. Huxley, \& R. E. Zirkle (Eds.), Progress in biophysics and biophysical chemistry (Vol. 12). New York: Pergamon Press, 1961.

Benjamin, R. M. Cortical taste mechanisms studied by two different test procedures. Journal of Comparative and Physiological Psychology, 1955, 48, 119-122. (a)

Benjamin, R. M. The effect of fluid deprivation on taste deficits following cortical lesions. Journal of Comparative and Physiological Psychology, 1955, 48, 502-505. (b)

Benjamin, R. M. The absence of deficits in taste discrimination following cortical lesions as a function of the amount of preoperative practice. Journal of Comparative and Physiological Psychology, 1959, 52, 255-258.

Benjamin, R. M. Effect of removal of olfactory bulbs on taste discrimination in normal and brain operated rats. The Physiologist, 1960, 3, 19. (Abstract)

Benjamin, R. M., \& AKert, K. Cortical and thalamic areas involved in taste discrimination in the albino rat. Journal of Comparative Neurology, 1959, 111, 231-259.

Benjamin, R. M., \& Pfaffmann, C. Cortical localization of taste in the albino rat. Journal of Neurophysiology, 1955, 18, 56-64.

Berger, B. D., Wise, C. D., \& Stein, L. Area postrema damage and bait shyness. Journal of Comparative and Physiological Psychology, 1973, 82, 475-479.

Best, P. J., \& Zuckerman, K. Subcortical mediation of learned taste aversion. Physiology \& Behavior, 1971, 7, 317-320.

Blomquist, A. J., Benjamin, R. M., \& Emmers, R. Thalamic localization of afferents from the tongue in squirrel monkeys (Saimiri sciureus). Journal of Comparative Neurology, 1962, 118, 77-87.

Blum, M., Ruch, T. C., \& Walker, A. E. Localization of taste in the thalamus of Macaca mulatta. Yale Journal of Biology and Medicine, 1943, 12, 719-736.

Börnste IN, W. S. The cortical taste area in monkeys and a semiquantitative method of testing taste in monkeys. American Journal of Physiology, 1940, 129, 314. (a)

Börnste in, W. S. Cortical representation of taste in man and monkey. I: Functional and anatomical relations of taste, olfaction, and somatic sensibility. Yale Journal of Biology and Medicine, 1940, 12, 719-736. (b)

Börnstein, W. S. Cortical representation of taste in man and monkey. II: The localization of the cortical taste area in man and a method of measuring impairment of taste in man. Yale Journal of Biology and Medicine, 1940, 13, 133-156. (c)

Braun, J. J. The neocortex and visual placing in rats. Brain Research, 1966, 1, 381-394.

Braun, J. J. Neocortex and feeding behavior in the rat. Journal of Comparative and Physiological Psychology, 1975, 89, 507-522.

Braun, J. J. Time and recovery from brain damage. In S. Finger (Ed.), Recovery from brain damage. New York: Plenum Press, 1978.

Braun, J. J., \& Kiefer, S. Preference-aversion functions for the basic taste stimuli in rats lacking gustatory neocortex. Bulletin of the Psychonomic Society, 1975, 6, 438-439. (Abstract)

Braun, J. J., Kiefer, S. W., \& Ouellet, J. V. Psychic ageusia in rats lacking gustatory neocortex. Experimental Neurology, 1981, 72, 711-716.

Braun, J. J., Le aCh, L, R., \& Kiefer, S. W. Psychic ageusia in rats lacking gustatory neocortex. Bulletin of the Psychonomic Society, 1978, 12, 267. (Abstract)

Braun, J. J., Lundey, E., \& McCarthy, F. Depth discrimination in rats following removal of visual neocortex. Brain Research, 1970, 20, 283-291.
Braun, J. J., \& Rosenthal, B. Relative salience of saccharin and quinine in long-delay taste aversion learning. Behavioral Biology, 1976, 16, 341-352.

Braun, J. J., \& Ryugo, R. A. Taste facilitation of a learned odor aversion. Bulletin of the Psychonomic Society, 1974, 4, 253. (Abstract)

Braun, J. J., Slick, T. B., \& Lorden, J. F. Involvement of gustatory neocortex in the learning of taste aversions. Physiology \& Behavior, 1972, 9, 637-641.

Burešova, O., \& Bureš, J. Cortical and subcortical components of conditioned saccharin aversion in rats. Acta Neurologia Experimentalis, 1973, 33, 689-698.

Burton, H., \& Benjamin, R. M. Central projections of the gustatory system. In L. M. Beidler (Ed.), Handbook of sensory physiology (Vol. 4): Chemical senses, 2. New York: SpringerVerlag, 1971.

Cooper, R. M., Freeman, I., \& Pinel, J. P. Absolute threshold of vision in the rat after removal of striate cortex. Journal of Comparative and Physiological Psychology, 1967, 64, 36-39.

Corey, D. T. The determinants of exploration and neophobia. Neuroscience and Biobehavioral Reviews, 1978, 2, 235-253.

Crosby, E. C., Humphrey, T., \& Lauer, E. W. Correlative anatomy of the nervous system. New York: Macmillan, 1962.

Divac, I., Gade, A., \& Wikmark, R. E. G. Taste aversion in rats with lesions in the frontal lobes: No evidence for interoceptive agnosia. Physiological Psychology, 1975, 3, 43-46.

Doetsch, G. S., \& Erickson, R. P. Synaptic processing of tastequality information in the nucleus tractus solitarius of the rat. Journal of Neurophysiology, 1970, 33, 490-507.

DomJan, M. Ingestional aversion learning: Unique and general processes. In J. Rosenblatt, R. Hinde, C. Beer, \& M. Busnel (Eds.), Advances in the study of behavior (Vol. 11). New York: Academic Press, 1980.

Eichenbaum, H., Shedlack, K. J., \& Eckmann, K. W. Thalamocortical mechanisms in odor-guided behavior. I. Effects of lesions of the mediodorsal thalamic nucleus and frontal cortex on olfactory discrimination in the rat. Brain, Behavior, and Evolution, 1980, 17, 255-275.

EMmers, R. Separate cortical receiving areas for gustatory and tongue tactile afferents in the rat. Anatomical Record, 1966, 154,460 .

EMmERS, R. Tonic control of water intake via the thalamic taste nucleus. Annals of the New York Academy of Sciences, 1977, 290, 124-138.

Emmers, R., Benjamin, R. N., \& Blomquist, A. J. Thalamic localization from the tongue in albino rats. Journal of Comparative Neurology, 1962, 118, 43-48.

ERICKson, R. P. Sensory neural patterns and gustation. In Y. Zotterman (Ed.), Olfaction and taste (Vol. 1). Oxford: Pergamon Press, 1963.

Ferrier, D. The functions of the brain. London: Smith, Elder, 1886.

Finger, S., Marshak, R. A., Cohen, M., Scheff, S., Trace, R., \& Neimand, D. Effects of successive and simultaneous lesions of somatosensory cortex on tactile discrimination in the rat. Journal of Comparative and Physiological Psychology, 1971, 77, 221-227.

Fink, R. P., \& Heimer, L. Two methods for selective silver impregnation of degenerating axons and their synaptic endings in the central nervous system. Brain Research, 1967, 4, 369-374.

FreGLY, M. J. Specificity of the sodium chloride appetite of adrenalectomized rats: Substitution of lithium chloride for sodium chloride. American Journal of Physiology, 1958, 195, 645-653.

French, R. L. The function of the cerebral cortex of the rat in the discrimination of simple auditory rhythms. Journal of Comparative Psychology, 1942, 33, 1-32.

Frommer, G. P. Gustatory afferent responses in the thalamus. In M. R. Kare \& B. Halpern (Eds.), The physiological and behavioral aspects of taste. Chicago: University of Chicago Press, 1961. 
Ganchrow, J. R., \& Erickson, R. P. Neural correlates of gustatory intensity and quality. Journal of Neurophysiology, 1970, 33, 768-783.

Ganchrow, D., \& Erickson, R. P. Thalamocortical relations in gustation. Brain Research, 1972, 36, 289-305.

Garcia, J., \& ERvin, F. R. Gustatory-visceral and telereceptorcutaneous conditioning: Adaptation in internal and external milieus. Communications in Behavioral Biology, 1968, 1, 389415.

Garcia, J., Ervin, F. R., Yorke, C. H., \& Koelling, R. A. Conditioning with delayed vitamin injections. Science, 1967, 155, 716-717.

Garcia, J., Kimeldorf, D. J., \& Koelling, R. A. Conditioned aversion to saccharin resulting from exposure to gamma radiation. Science, 1955, 122, 157-158.

Garcia, J., \& Rusiniak, K. W. What the nose learns from the mouth. In D. Muller-Schwarze \& R. N. Silverstein (Eds.), Chemical signals. New York: Plenum Press, 1980.

Giachetti, I., \& MacLeod, P. Olfactory input to the thalamus: Evidence for a ventroposteromedial projection. Brain Research, 1977, 125, 166-169.

Gold, R. M., \& Proulx, D. M. Bait-shyness acquisition is impaired by VMH lesions that produce obesity. Journal of Comparative and Physiological Psychology, 1972, 79, 201-209.

GoldBe RGER, M. E. Recovery of movement after CNS lesions in monkeys. In D. G. Stein, J. J. Rosen, \& N. Butters (Eds.), Plasticity and recovery of function in the central nervous system. New York: Academic Press, 1974.

Grill, H. J. Sucrose as an aversive stimulus. Neuroscience $A b$ stracts, 1975, 1, 525.

Grill, H. J., \& Norgren, R. The taste reactivity test. I. Mimetic responses to gustatory stimuli in neurologically normal rats. Brain Research, 1978, 143, 263-279. (a)

Grill, H. J., \& Norgren, R. The taste reactivity test. II. Mimetic responses to gustatory stimuli in chronic thalamic and chronic decerebrate rats. Brain Research, 1978, 143, 281-297. (b)

Grill, H. J., \& Norgren, R. Chronic decerebrate rats demonstrate satiation but not bait-shyness. Science, 1978, 201, 267269. (c)

Hankins, W. G., Garcia, J., \& Rusiniak, K. W. Cortical lesions: Flavor illness and noise-shock conditioning. Behavioral Biology, 1974, 10, 173-181.

HeAD, H., \& Holmes, G. Sensory disturbance from cerebral lesions. Brain, 1911, 34, 102-225.

Horel, J. A., Bettinger, L. A., Royce, G. J., \& Meyer, D. R. Role of neocortex in the learning and relearning of two visual habits by the rat. Journal of Comparative and Physiological Psychology, 1966, 61, 66-78.

Hull, C. L. Stimulus intensity dynamism (V) and stimulus generalization. Psychological Review, 1949, 56, 67-76.

JACKson, J. H. Evolution and dissolution of the nervous system. In J. Taylor (Ed.), Selected writings of John Hughlings Jackson (Vol. 2). New York: Basic Books, 1958. (Originally published, 1884.)

JACOBS, H. L. The osmotic postingestion factor in the regulation of glucose appetite. In M. R. Kare \& B. P. Halpern (Eds.), The physiological and behavioral aspects of taste. Chicago: University of Chicago Press, 1961

KALAT, J. W. Taste salience depends on novelty, not concentration, in taste-aversion learning in the rat. Journal of Comparative and Physiological Psychology, 1974, 86, 47-50.

Kalat, J. W., \& Rozin, P. "Salience": A factor which can override temporal contiguity in taste-aversion learning. Journal of Comparative and Physiological Psychology, 1970, 71, 192-197.

KALAT, J. W., \& RoziN, P. "Learned safety" as a mechanism in long-delay taste-aversion learning in rats. Journal of Comparative and Physiological Psychology, 1973, 83, 198-207.

Kawamura, U., Kasahara, Y., \& Funakoshi, M. A possible brain mechanism for rejection behavior to strong salt solution. Physiology \& Behavior, 1970, 5, 67-74.

KIEFER, S. W. Two-bottle discrimination of equimolar $\mathrm{NaCl}$ and
LiCl solutions by rats. Physiological Psychology, 1978, 6, 191198.

Kiefer, S. W., \& Braun, J. J. Absence of differential associative responses to novel and familiar taste stimuli in rats lacking gustatory neocortex. Journal of Comparative and Physiological Psychology, 1977, 91, 498-507.

KIEFER, S. W., \& Braun, J. J. Acquisition of taste avoidance habits in rats lacking gustatory neocortex. Physiological Psychology, 1979, 7, 245-250.

Kiefer, S. W., Rusiniak, K. W., \& Garcia, J. Flavor-illness aversions: Potentiation of odor by taste in rats with gustatory neocortex ablations. Journal of Comparative and Physiological Psychology, in press.

KolB, B., \& Nonneman, A. Prefrontal cortex and the regulation of food intake in the rat. Journal of Comparative and Physiological Psychology, 1975, 88, 806-815.

KRAL, P. A. Interpolation of electroconvulsive shock during CSUS interval as an impediment to the conditioning of taste aversion. Psychonomic Science, 1970, 19, 36-37.

Kratz, C. M., \& Levitsky, D. A. Post-ingestive effects of quinine on intake of nutritive and non-nutritive substances. Physiology \& Behavior, 1978, 21, 851-854.

Krettek, J. E., \& Price, J. L. A direct input from the amygdala to the thalamus and the cerebral cortex. Brain Research, 1974, 67, 169-174.

Krettek, J. E., \& Price, J. L. The cortical projection of the medio-dorsal nucleus and adjacent thalamic nuclei in the rat. Journal of Comparative Neurology, 1977, 171, 157-192. (a)

Krettek, J. E., \& Price, J. L. Projections from the amygdaloid complex to the cerebral cortex and thalamus in the rat and cat. Journal of Comparative Neurology, 1977, 172, 687-722. (b)

Krette K, J. E., \& Price, J. L. Projections from the amygdaloid complex and adjacent olfactory structures to the entorhinal cortex and to the subiculum in the rat and cat. Journal of Comparative Neurology, 1977, 172, 723-752. (c)

Krettek, J. E., \& Price, J. L. Amygdaloid projections to subcortical structures within the basal forebrain and brainstem in the rat and cat. Journal of Comparative Neurology, 1978, 178, 225-254.

KriecKhaUs, E. E. "Innate recognition" aids rats in sodium regulation. Journal of Comparative and Physiological Psychology, 1970, 73, 117-122.

LADD, G. T. Elements of physiological psychology. New York: Scribner's, 1887.

LASHLEY, K. S. Studies of cerebral function in learning. II. The effects of long continued practice upon cerebral localization. Journal of Comparative Psychology, 1921, 1, 453-468.

LASHLEY, K. S. The mechanism of vision: II. The influence of cerebral lesions upon the threshold of discrimination for brightness in the rat. Journal of Genetic Psychology, 1930, 37, 461-480.

LASHLEY, K. S. The mechanism of vision: XII. Nervous structures concerned in habits based on reactions to light. Comparative Psychology Monograph, 1935, 11, 43-79.

LASHLEY, K. S. The mechanism of vision: XVII. Autonomy of the visual cortex. Journal of Genetic Psychology, 1942, 60, 197-221.

LASHLEY, K. S. In search of the engram. Symposium of the Society of Experimental Biology, 1950, 4, 454-482.

LASHLEY, K. S. Studies of cerebral functions in learning. XI. The behavior of the rat in the latch box situations. In F. A. Beach, D. O. Hebb, C. T. Morgan, \& H. W. Nissen (Eds.), The neuropsychology of Lashley. New York: McGraw-Hill, 1960. (Originally published, 1935.)

Lasiter, P. S., \& Glanzman, D. L. Cortical substrates of taste aversion learning: Dorsal prepiriform (insular) lesions disrupt taste aversion learning. Journal of Comparative and Physiological Psychology, 1982, 96, 376-392.

Lasiter, P. S., Glanzman, D. L., \& Mensah, P. A. Direct connectivity between pontine taste areas and gustatory neocortex in rat. Brain Research, 1982, 234, 111-121.

Lehr, P. P., \& Nachman, M. Lateralization of learned taste 
aversion by cortical spreading depression. Physiology \& Behavior, $1973,10,79-83$.

LEONARD, C. M. The prefrontal cortex of the rat. I. Cortical projection of the mediodorsal nucleus. II. Efferent connections. Brain Research, 1969, 12, 321-343.

Leonard, C. M. The connections of the dorsomedial nuclei. Brain, Behavior and Evolution, 1972, 6, 524-541.

LEVERE, T. E. Recovery of function after brain damage: A theory of the behavioral deficit. Physiological Psychology, 1980, 8, 297-308.

LeVere, T. E., \& Mills, J. Residual differential brightness thresholds following removal of visual neocortex in rats. Physiological Psychology, 1977, 5, 490-496.

LORDEN, J. F. Effects of lesions of the gustatory neocortex on taste aversion learning. Journal of Comparative and Physiological Psychology, 1976, 90, 665-679.

Loullis, C. C., Wayner, M. J., \& Jolicoeur, F. B. Thalamic taste nuclei lesions and taste aversion learning. Physiology \& Behavior, 1978, 20, 653-655.

LuRIA, A. R. Higher cortical functions in man. New York: Basic Books, 1966.

MACHT, M. B. Subcortical localization of certain "taste" responses in the cat. Federation Proceedings, 1951, 10, 88. (Abstract)

Maclean, P. D. Cerebral evolution and emotional processes. Annals of the New York Academy of Sciences, 1972, 193, 137-149.

McBurney, D. H. Are there primary tastes for man? In Chemical senses and flavor (Vol. 1). Dordrecht: Reidel, 1974.

MCCleary, R. A. Taste and postingestion factors in specific hunger behavior. Journal of Comparative and Physiological Psychology, 1953, 46, 411-421.

McCle ARY, R. A. Response-modulating functions of the limbic system: Initiation and suppression. In E. Stellar \& J. Sprague (Eds.), Progress in physiological psychology (Vol. 1). New York: Academic Press, 1966.

McGowan, B. K., Garcia, J., Ervin, F. R., \& Schwartz, J. Effects of septal lesions on bait-shyness in the rat. Physiology \& Behavior, 1969, 4, 907-909.

McGowan, B. K., Hankins, W. G., \& Garcia, J. Limbic lesions and control of the internal and external environment. Behavioral Biology, 1972, 7, 841-852.

Meyer, D. R. Access to engrams. American Psychologist, 1972, 27, 124-133.

MEYeR, D. R., \& Beattie, M. S. Some properties of substrates of memory. In L. H. Miller, C. A. Sandman, \& A. J. Kastin (Eds.), Neuropeptide influences of the brain and behavior. New York: Raven Press, 1977.

MeYer, D. R., \& MEYer, P. M. Dynamics and bases of recoveries of functions after injuries to the cerebral cortex. Physiological Psychology, 1977, 5, 133-165.

Miller, C. R., Elkins, R. L., \& Peacock, L. J. Disruption of a radiation-induced preference shift by hippocampal lesions. Physiology \& Behavior, 1971, 6, 283-285.

Miller, S. D., \& Erickson, R. P. The odor of taste solutions. Physiology \& Behavior, 1966, 1, 145-146.

Mook, D. G. Oral and postingestion factors in specific hunger behavior. Journal of Comparative and Physiological Psychology, 1963, 56, 654-659.

Morest, D. K. Experimental study of the projections of the nucleus of the tractus solitarius and the area postrema in the cat. Journal of Comparative Neurology, 1967, 130, 277-300.

Munk, H. Über die Functionen der Grosshirnrinde. Berlin: Hirschwald, 1890.

Nachman, M. Learned aversion to the taste of lithium chloride and generalization to other salts. Journal of Comparative and Physiological Psychology, 1963, 56, 343-349.

Nachman, M. Limited effects of electroconvulsive shock on memory of taste stimulation. Journal of Comparative and Physiological Psychology, 1970, 73, 31-37.

Nachman, M., \& Ashe, J. H. Effects of basolateral amygdala lesions on neophobia, learned taste aversions, and sodium ap- petite in rats. Journal of Comparative and Physiological Psychology, 1974, 87, 622-643.

NADAL, L. Interhemispheric transfer: Monocular input and varied sensory conditions. Physiology \& Behavior, 1971, 6, 655-661.

NaUtA, W. J. H. Silver impregnation of degenerating axons. In W. F. Windle (Ed.), New research techniques of neuroanatomy. Springfield, Ill: Thomas, 1957.

Norgren, R. Gustatory responses in the hypothalamus. Brain Research, 1970, 21, 63-77. (a)

Norgren, R. Behavioral correlates of the thalamic gustatory area. Brain Research, 1970, 22, 221-230. (b)

NorgREN, R. Gustatory afferents to ventral forebrain. Brain Research, 1974, 81, 285-295.

Norgren, R. Taste pathways to hypothalamus and amygdala. Journal of Comparative Neurology, 1976, 166, 17-30.

Norgren, R. A synopsis of gustatory neuroanatomy. In J. LeMagnen \& P. MacLeod (Eds.), Olfaction and taste VI. London: Information Retrieval, 1977.

Norgren, R. Projections from the nucleus of the solitary tract in rat. Neuroscience, 1978, 3, 207-218.

Norgren, R., \& LeonARD, C. M. Taste pathways in rat brainstem. Science, 1971, 173, 1136-1139.

Norgren, R., \& Leonard, C. M. Ascending central gustatory connections. Journal of Comparative Neurology, 1973, 150, 217-238.

Norgren, R., \& Pfaffmann, C. The pontine taste area in the rat. Brain Research, 1975, 91, 99-117.

Norgren, R., \& WolF, G. Projections of thalamic gustatory and lingual areas in the rat. Brain Research, 1975, 92, 123-129.

Nowlis, G. H. Taste elicited tongue movements in human newborn infants: An approach to palatability. In J. F. Bosma (Ed.), Fourth Symposium on Oral Sensation and Perception: Development in the fetus and infant (Department of Health, Education, and Welfare Publication No. NIH 73-546). Washington, D.C: U.S. Government Printing Office, 1973.

Nowlis, G. H. Conditioned stimulus intensity and acquired alimentary aversions in the rat. Journal of Comparative and Physiological Psychology, 1974, 86, 1173-1184.

NowhIs, G. H. From reflex to representation: Taste-elicited tongue movements in the human newborn. In J. M. Weiffenbach (Ed.), Taste and development: The genesis of sweet preference (Department of Health, Education, and Welfare Publication No. NIH 77-1068). Washington, D.C: U.S. Government Printing Office, 1977.

Nowlis, G. H., \& Kessen, W. Human newborns differentiate differing concentrations of sucrose and glucose. Science, 1976, 191, 865-866.

OAKLEY, B. Impaired operant behavior following lesions of the thalamic taste nucleus. Journal of Comparative and Physiological Psychology, 1965, 59, 202-210.

OAKLey, B., \& Pfaffmann, C. Electrophysiologically monitored lesions in the gustatory thalamic relay of the albino rat. Journal of Comparative and Physiological Psychology, 1962, 55, 155-160.

PAPEz, J. W. A proposed mechanism of emotion. American Medical Association Archives of Neurology and Psychiatry, 1937, 38, $725-743$.

Patton, H. D. Physiology of smell and taste. Annual Review of Physiology, 1950, 12, 469-484.

Patton, H. D. Taste, olfaction and visceral sensation. In J. F. Fulton (Ed.), A textbook of physiology (17th ed.). Philadelphia: Saunders, 1955.

Patton, H. D., \& Amassian, V. E. Cortical projection zone of chorda typani nerve in cat. Journal of Neurophysiology, 1952, 15, 245-250.

PatTon, H. D., \& Ruch, T. C. Howell's textbook of physiology (15th ed.). Philadelphia: Saunders, 1946.

Patton, H. D., Ruch, T. C., \& Fulton, J. F. The relation of the foot of the pre- and postcentral gyrus to taste in the monkey and chimpanzee. Federation Proceedings, 1946, 5, 79.

Patton, H. D., Ruch, T. C., \& Walker, A. E. Experimental hypogeusia from Horsley-Clarke lesions of the thalamus in 
Macaca mulatta. Journal of Neurophysiology, 1944, 7, 171-184.

Pavlov, I. P. Conditioned reflexes. New York: Dover, 1960. (Originally published, 1927.)

Pellegrino, L. Amygdaloid lesions and behavioral inhibition in the rat. Journal of Comparative and Physiological Psychology, 1968, 65, 483-491.

Perrotto, R. S., \& Scott, T. R. Gustatory neural coding in the pons. Brain Research, 1976, 110, 283-300.

Petrinovich, L. Cortical spreading depression and memory transfer: A methodological critique. Behavioral Biology, 1976, 16, 79-84.

Pfaffmann, C. Gustatory afferent impulses. Journal of Cellular and Comparative Physiology, 1941, 17, 243-258.

Pfaffmann, C. The sense of taste. In J. Field, H. W. Magoun, \& V. E. Hall (Eds.), Handbook of physiology (Vol. 1). Washington, D.C: American Physiological Society, 1959.

Pfaffmann, C. The pleasures of sensation. Psychological Review, 1960, 67, 253-268.

Pfaffmann, C. De Gustibus. American Psychologist, 1965, 20, 21-33.

Pfaffmann, C. Taste preference and reinforcement. In J. Tapp (Ed.), Reinforcement and behavior. New York: Academic Press, 1969.

Praffmann, C. Physiological and behavioral processes of the sense of taste. In G. Wolstenholme \& J. Knight (Eds.), Ciba Foundation Symposium on Taste and Smell in Vertebrates. London: Churchill, 1970.

Pfaffmann, C., Frank, M., \& Norgren, R. Neural mechanisms and behavioral aspects of taste. Annual Review of Psychology, 1979, 30, 283-325.

Pfaffmann, C., Norgren, R., \& Grill, H. J. Sensory affect and motivation. Annals of the New York Academy of Science, 1977, 290, 18-34.

Phillips, J. Taste discrimination, generalization, and the gustatory neocortex. Unpublished master's thesis, Arizona State University, 1977.

Powell, T. P. S., Cowan, W. M., \& Raisman, G. The central olfactory connexions. Journal of Anatomy, 1965, 99, 791-813.

Rescorla, R. A., \& W AGner, A. R. A theory of Pavlovian conditioning: Variations in the effectiveness of reinforcement. In A. H. Black \& W. F. Prokasy (Eds.), Classical conditioning (Vol. 2): Current research and theory. New York: AppletonCentury-Crofts, 1972.

Revusky, S. H., \& Bedarf, E. W. Association of illness with ingestion of novel foods. Science, 1967, 155, 219-220.

Revusky, S., \& Garcia, J. Learned associations over long delays. In G. H. Bower \& J. T. Spence (Eds.), Psychology of learning and motivation: Advances in research and theory (Vol. 4). New York: Academic Press, 1970.

Ricardo, J. A., \& Кон, E. T. Anatomical evidence of direct projections from the nucleus of the solitary tract to the hypothalamus, amygdala, and other forebrain structures in the rat. Brain Research, 1978, 153, 1-26.

Richte R, C. P. Salt taste thresholds of normal and adrenalectomized rats. Endocrinology, 1939, 24, 367-371.

RiChTE R, C. P. Self-regulatory functions. Harvey Lectures, 1942, Series 38, 63-103.

RICHTER, C. P. Experimentally produced behavior reactions to food poisoning in wild and domesticated rats. Annals of the New York Academy of Sciences, 1953, 56, 225-239.

Roll, D. L., \& SмIтH, J. C. Conditioned taste aversion in anesthetized rats. In M. E. P. Seligman \& J. L. Hager (Eds.), Biological boundaries of learning. New York: Appleton-CenturyCrofts, 1972.

Rolls, B. J., \& Rolls, E. T. Effects of lesions in the basolateral amygdala on fluid intake in the rat. Journal of Comparative and Physiological Psychology, 1973, 83, 240-247.

Roth, S. R., Schwartz, M., \& Teitelbaum, P. Failure of recovered lateral hypothalamic rats to learn specific food aversions. Journal of Comparative and Physiological Psychology, 1973, 83, 184-197.

Rozin, P., \& Kalat, J. W. Specific hungers and poison avoidance as adaptive specializations of learning. Psychological Review, 1971, 78, 459-486.

Ruch, T. C., Patton, H. D., Woodbury, J. W., \& Towe, A. L. Neurophysiology (6th ed.). Philadelphia: Saunders, 1966.

Ruderman, M. I., Morrison, A. R., \& Hand, P. J. A solution to the problem of cerebral cortical localization of taste in cat. Experimental Neurology, 1972, 37, 522-537.

RzoskA, J. Bait shyness, a study in rat behaviour. British Journal of Animal Behaviour, 1953, 1, 128-135.

Schwartz, J., \& Teitelbaum, P. Dissociation between learning and remembering in rats with lesions in the lateral hypothalamus. Journal of Comparative and Physiological Psychology, 1974, 87, 384-398.

ScotT, T. R. Behavioral support for a neural taste theory. Physiology \& Behavior, 1974, 12, 413-417.

ScotT, T. R., \& Erickson, R. P. Synaptic processing of tastequality information in the thalamus of the rat. Journal of Neurophysiology, 1971, 34, 668-684.

Scott, T. R., \& Perrotto, R. S. Intensity coding in pontine taste area: Gustatory information is processed similarly throughout rat's brain stem. Journal of Neurophysiology, 1980, 44, 739-749.

Smith, D. F., \& Balagura, S. Role of oropharyngeal factors in $\mathrm{LiCl}$ aversion. Journal of Comparative and Physiological Psychology, 1969, 69, 308-310.

Sмiтh, J. C., \& Roll, D. L. Trace conditioning with X-rays as an aversive stimulus. Psychonomic Science, 1967, 9, 11-12.

Sмiтн, K. U. The postoperative effects of removal of the striate cortex upon certain unlearned visually controlled reactions in the cat. Journal of Genetic Psychology, 1937, 50, 137-156.

SмIтн, K. U. Visual discrimination in the cat: VI. The relation between pattern vision and visual acuity and the optic projection centers of nervous system. Journal of Genetic Psychology, 1938, 53, 251-272.

SPE AR, P. D. Behavioral and neurophysiological consequences of visual cortex damage: Mechanisms of recovery. In J. M. Sprague \& A. N. Epstein (Eds.), Progress in psychobiology and physiological psychology (Vol. 8). New York: Academic Press, 1979.

Spear, P. D., \& Braun, J. J. Nonequivalence of normal and posteriorly neodecorticated rats on two brightness discrimination problems. Journal of Comparative and Physiological Psychology, 1969, 67, 235-239.

SPERRY, R. W. Effect of crossing nerves to antagonistic limb muscles in the monkey. Archives of Neurology and Psychiatry, $1947,58,452-473$.

Steiner, J. E. The human gustofacial response. In J. F. Bosma (Ed.), Fourth Symposium on Oral Sensation and Perception: Development in the fetus and infant (Department of Health, Education, and Welfare Publication No. NIH 73-546). Washington, D.C: U.S. Government Printing Office, 1973.

Stellar, E., \& McCleary, R. A. Food preference as a function of the method of measurement. American Psychologist, 1952, $7,256$.

TAPPER, D. N., \& HAlPenN, B. P. Taste stimuli: A behavioral categorization. Science, 1968, 161, 708-710.

Torvik, A. Afferent connections to the sensory trigeminal nuclei, the nucleus of the solitary tract and adjacent structures. An experimental study in the rat. Journal of Comparative Neurology, 1956, 106, 51-141.

VosharT, K., \& VAN DER Kooy, D. The organization of the efferent projections of the parabrachial nucleus to the forebrain in the rat: A retrograde fluorescent double-labeling study. Brain Research, 1981, 212, 271-286.

WALKER, A. E. An experimental study of the thalamocortical projection of the macaque monkey. Journal of Comparative Neurology, 1934, 64, 1-39.

WALKer, A. E. The primate thalamus. Chicago: University of Chicago Press, 1938.

Winn, R. F., Kent, M. A., \& Libkuman, T. Learned taste aversion induced by cortical spreading depression. Physiology \& Behavior, 1975, 15, 21-24.

Wirsig, C. R., \& Grill, H. J. The contribution of the rat's 
neocortex to ingestive control: I. Latent learning for the taste of sodium chloride. Journal of Comparative and Physiological Psychology, in press.

WoLF, G. Projections of thalamic and cortical gustatory areas in the rat. Journal of Comparative Neurology, 1968, 132, 519-530.

WoLF, G. Innate mechanisms for regulation of sodium intake. In C. Pfaffmann (Ed.), Olfaction and taste: Proceedings of the Third International Symposium. New York: Rockefeller University Press, 1969.

Wolf, G., DiCara, L., \& Braun, J. Sodium appetite in rats after neocortical ablation. Physiology \& Behavior, 1970, 5, 1265-1269.

Wood, C. C., Spear, P. D., \& Braun, J. J. Direction-specific deficits in horizontal optokinetic nystagmus following removal of visual cortex in the cat. Brain Research, 1973, 60, 231-237.

Woolsey, C. N. Organization of somatic sensory and motor areas of the cerebral cortex. In H. F. Harlow \& C. N. Woolsey (Eds.), Biological and biochemical bases of behavior. Madison: University of Wisconsin Press, 1958.

Woolsey, C. N., \& Le Messurier, D. H. Pattern of cutaneous representation in the rat's cerebral cortex. Federation Proceedings, 1948, 7, 137-138.

Yамамото, T., \& Kawamura, Y. Summated cerebral responses to taste stimuli in rat. Physiology \& Behavior, 1972, 9, 789-793.

YAMAMoto, T., \& KaWAmuRA, Y. Cortical responses to electrical and gustatory stimuli in the rabbit. Brain Research, 1975, 94, 447-463.

Yamamoto, T., Matsuo, R., \& Kawamura, Y. Localization of cortical gustatory area in rats and its role in taste discrimination. Journal of Neurophysiology, 1980, 44, 440-454.

Yamamoto, T., Yuyama, N., \& Kawamura, Y. Cortical neurons responding to tactile, thermal and taste stimulations of the rat's tongue. Brain Research, 1981, 221, 202-206.

Young, P. T. Hedonic organization and regulation of behavior. Psychological Review, 1966, 73, 59-86.

Zotte Rman, Y. Species differences in the water taste. Acto Physiologica Scandinavica, 1956, 37, 60-70.

ZotTERMAN, Y. Discussion of cortical gustatory projection area on p. 112. In G. E. W. Wolstenholme \& J. Knight (Eds.), Taste and smell in vertebrates. London: Churchill, 1970.

ZUBE K, J. P. Studies in somesthesis. I. Role of the somesthetic cortex in roughness discrimination in the rat. Journal of Comparative and Physiological Psychology, 1951, 44, 339-353.

\section{NOTES}

1. The identification of taste-chemical concentrations has been converted to millimolar units (mM) for ease of presentation and for consistency throughout this paper.

2. The word "ageusia" is used operationally to mean behavioral evidence of an inability to taste.

(Manuscript received February 6, 1982; accepted for publication February 10, 1982.) 